\title{
Anterior Thalamic Excitation and Feedforward Inhibition of Presubicular Neurons Projecting to Medial Entorhinal Cortex
}

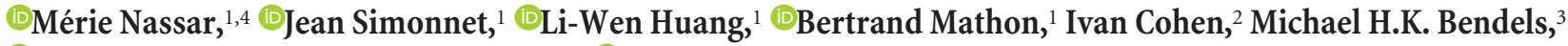 \\ @Mathieu Beraneck, ${ }^{4}$ Richard Miles, ${ }^{1}$ and ${ }^{-D e s d e m o n a ~ F r i c k e r ~}{ }^{1,4}$ \\ ${ }^{1}$ Institut National de la Santé et de la Recherche Médicale U1127, Centre National de la Recherche Scientifique Unité Mixte de Recherche 7225, Sorbonne \\ Universités, UPMC Université Paris 6, Unité Mixte de Recherche S1127, Institut du Cerveau et de la Moelle épinière, 75013 Paris, France, ${ }^{2}$ Institut National \\ de la Santé et de la Recherche Médicale U1130, Centre National de la Recherche Scientifique Unité Mixte de Recherche 8246, UPMC Neuroscience Paris \\ Seine, 75005 Paris, France, ${ }^{3}$ Institut of Occupational, Social and Environmental Medicine, Goethe University, 60590 Frankfurt, Germany, and ${ }^{4} \mathrm{Centre}$ \\ National de la Recherche Scientifique Unité Mixte de Recherche 8119, Université Paris Descartes, 75006 Paris, France
}

The presubiculum contains head direction cells that are crucial for spatial orientation. Here, we examined the connectivity and strengths of thalamic inputs to presubicular layer 3 neurons projecting to the medial entorhinal cortex in the mouse. We recorded pairs of projection neurons and interneurons while optogenetically stimulating afferent fibers from the anterior thalamic nuclei. Thalamic input differentially affects presubicular neurons: layer 3 pyramidal neurons and fast-spiking parvalbumin-expressing interneurons are directly and monosynaptically activated, with depressing dynamics, whereas somatostatin-expressing interneurons are indirectly excited, during repetitive anterior thalamic nuclei activity. This arrangement ensures that the thalamic excitation of layer 3 cells is often followed by disynaptic inhibition. Feedforward inhibition is largely mediated by parvalbumin interneurons, which have a high probability of connection to presubicular pyramidal cells, and it may enforce temporally precise head direction tuning during head turns. Our data point to the potential contribution of presubicular microcircuits for fine-tuning thalamic head direction signals transmitted to medial entorhinal cortex.

Key words: head direction; hippocampus; interneurons; optogenetics; patch clamp; postsubiculum

Significance Statement

How microcircuits participate in shaping neural inputs is crucial to understanding information processing in the brain. Here, we show how the presubiculum may process thalamic head directional information before transmitting it to the medial entorhinal cortex. Synaptic inputs from the anterior thalamic nuclei excite layer 3 pyramidal cells and parvalbumin interneurons, which mediate disynaptic feedforward inhibition. Somatostatin interneurons are excited indirectly. Presubicular circuits may switch between two regimens depending on the angular velocity of head movements. During immobility, somatostatin-pyramidal cell interactions could support maintained head directional firing with attractor-like dynamics. During rapid head turns, in contrast, parvalbumin-mediated feedforward inhibition may act to tune the head direction signal transmitted to medial entorhinal cortex.

\section{Introduction}

The presubiculum is part of the parahippocampal cortex, located between the hippocampus and the entorhinal cortex (Amaral and

Received Jan. 3, 2018; revised April 17, 2018; accepted May 8, 2018.

Author contributions: M.N. and D.F. wrote the first draft of the paper; J.S., M.B., R.M., and D.F. edited the paper; M.N., J.S., and D.F. designed research; M.N., J.S., and L.-W.H. performed research; B.M. and M.H.K.B. contributed unpublished reagents/analytic tools; M.N., J.S., I.C., M.B., R.M., and D.F. analyzed data; M.N. and D.F. wrote the paper.

This work was supported by the French Ministry for Education and Research to M.N., Centre National des Etudes Spatiales to M.N. and M.B., Région lle-de-France to J.S., and Agence nationale de la recherche Grant JCJC R10206DD to D.F. The research leading to these results also benefitted from the program "Investissements d'avenir" ANR-10IAIHU-06. This work was supported in part by ERC 322721 to R.M. We thank Nathalie Sol-Foulon for help with confocal imaging; and Karl Deisseroth for making available pAAV-hSyn-hChR2(H134R)-eYFP and pAAV-Ef1a-DIO eNpHR 3.0-EYFP.
Witter, 1989; van Strien et al., 2009). It plays a fundamental role in the perception of spatial orientation. Most presubicular neurons of layer 3 and some in deeper layers signal head direction (Boccara et al., 2010; Preston-Ferrer et al., 2016). These cells fire persistently when the head of an animal is oriented in a specific direction, and some presubicular head direction cells of layer 3 project to medial entorhinal cortex (MEC) (Tukker et al., 2015;

\footnotetext{
The authors declare no competing financial interests.
}

Correspondence should be addressed to Dr. Desdemona Fricker, Université Paris Descartes, Centre National de la Recherche Scientifique Unité Mixte de Recherche 8119, 45 rue des St-Pères, 75006 Paris, France. E-mail: desdemona.fricker@parisdescartes.fr.

DOI:10.1523/JNEUROSCI.0014-18.2018

Copyright $\odot 2018$ the authors $\quad 0270-6474 / 18 / 386411-15 \$ 15.00 / 0$ 
Preston-Ferrer et al., 2016). Presubicular fast-spiking interneurons are modulated by angular velocity (Preston-Ferrer et al., 2016). Head direction information originates subcortically, mostly from vestibular inputs (Stackman and Taube, 1997; Bassett et al., 2007). The anterior thalamic nucleus (ATN) relays these signals to the presubiculum (van Groen and Wyss, 1990a,b, 1995; Taube, 2007; Peyrache et al., 2015). Lesions of the anterior thalamus abolish head direction firing and impair grid cell signals in parahippocampal cortex (Goodridge and Taube, 1997; Winter et al., 2015). In the presubiculum, thalamic head direction signals (Taube, 1995) are integrated with visual information from visual (Vogt and Miller, 1983) and retrosplenial cortices (van Groen and Wyss, 1990a,c). Neurons of the ATN also contribute to spatial firing of grid cells of MEC (McNaughton et al., 2006; Langston et al., 2010, Winter et al., 2015). The presubicular projection may therefore transmit ATN-derived head direction signals to the medial entorhinal grid cell system (Rowland et al., 2013; Preston-Ferrer et al., 2016). However, it is unclear whether thalamic axons contact presubicular cells that project to the MEC.

Recent work has revealed some properties of circuits involving presubicular principal cells and interneurons (Simonnet et al., 2013; Nassar et al., 2015; Peng et al., 2017). Local interactions between pyramidal cells (PCs) and somatostatin (SST)-expressing Martinotti cells may help sustain firing in head direction cells ( $\mathrm{Si}$ monnet et al., 2017). The role of fast-spiking parvalbumin (PV)positive interneurons in processing thalamic head directional information remains to be clarified, however. Here we examine the hypothesis that these interneurons mediate a feedforward inhibitory control of head direction signals transmitted to the grid cell system. We used electrophysiology, optogenetics, and retrograde labeling to examine how presubicular PV cells and PCs process excitatory inputs from the ATN. Our data show that ATN axons directly contact pyramidal MEC-projecting neurons and PV interneurons of layer 3. PV interneurons mediate feedforward inhibition, and their recruitment is strongest at the onset of ATN spiking.

\section{Materials and Methods}

Animals. Experiments were performed on male and female offspring of male Pvalb-Cre mice (RRID:IMSR_JAX:008069) (Hippenmeyer et al., 2005) or Sst-IRES-Cre mice (RRID:IMSR_JAX:013044) (Taniguchi et al., 2011) crossed with the Ai14 Cre reporter line (RRID:IMSR_JAX:007914) (Madisen et al., 2010). Cre-mediated recombination resulted in the expression of red fluorescent tdTomato labeling in Pvalb-Cre or SST-Cre neurons. Wild-type Bl6 and Pvalb-Cre males were used for double injections. Animal care and use conformed to the European Community Council Directive of September 22, 2010 (2010/63/EU) and French law (87/848). Our study was approved by the ethics committee Charles Darwin No. 5 and the French Ministry for Research 01025.02.

Viral vectors. Viral vectors were injected to induce expression of channelrhodopsin and halorhodopsin. AAV2.hSyn.hChR2(H134R)-eYFP. WPRE.hGH (Penn Vector Core, Addgene 26973P) with serotypes 5 or 9, contained an enhanced ChR2-EYFP fusion gene, driven by a hSynapsin promoter. We also used AAV1.EF1a.DIO.eNpHR3.0-eYFP.WPRE.Hgh (Penn Vector Core, Addgene 26966), an adeno-associated virus (AAV) serotype 1 carrying Cre-inducible halorhodopsin-3.0 (eNpHR3.0)enhanced yellow fluorescent protein (eYFP) transgene driven by EF1a promoter for optogenetic inhibition. Viral vectors were stored in aliquots at $-80^{\circ} \mathrm{C}$ until use.

Stereotaxic surgery. Mice, of age 25-35 d, were anesthetized intraperitoneally with ketamine hydrochloride and xylazine $(100$ and $15 \mathrm{mg} / \mathrm{kg}$, respectively) and placed in a stereotaxic frame. Unilateral viral injections were performed as described previously (Mathon et al., 2015). AAV injections were targeted to ATN using coordinates from bregma of lateral, $0.75 \mathrm{~mm}$; posterior, $-0.82 \mathrm{~mm}$; and depth, $3.2 \mathrm{~mm}$. Injections were made with a Hamilton syringe using a syringe Pump Controller (Harvard
Apparatus, Pump 11 elite) at $60 \mathrm{nl} / \mathrm{min}$ to deliver volumes of $150-300 \mathrm{nl}$ hSyn-ChR2 AAV2/5 or AAV2/9 vectors. Leakage from an injection site to surrounding tissue was minimized by withdrawing the pipette slowly after a delay of $5 \mathrm{~min}$. Maximal transgene expression occurred 2 weeks after AVV2/9 and 3 weeks after AAV2/5 injection. Viral titers for AAV2/5 and AAV2/9 vectors were, respectively, $1.3 \times 10^{13}$ and $3.39 \times 10^{13}$ virus particles/ml. Because light-evoked responses were similar for ChR2 expression by either AAV serotype, results were pooled. We also made double injections of AAV in ATN and a retrograde tracer in MEC. Presubicular projecting neurons were labeled retrogradely by red fluorescent latex microspheres (Lumafluor; volume $300 \mathrm{nl}$ ) injected in the ipsilateral MEC at coordinates from bregma for MEC of lateral, $3 \mathrm{~mm}$; posterior, $-4.7 \mathrm{~mm}$; and depth, $4 \mathrm{~mm}$. Finally, we made double injections of AAVChR2 in ATN and AAV-eNpHR3.0 in the presubiculum of Pvalb-Cre mice to express halorhodpsin selectively in PV interneurons. AAV-EF1aDIO-eNpHR3.0-EYFP was injected (final volume $350 \mathrm{nl}$ ) in the presubiculum at coordinates from bregma of lateral $2 \mathrm{~mm}$; posterior -4.06 $\mathrm{mm}$; and depth $2.15 \mathrm{~mm}$. The viral titer was $1.09 \times 13$ particles $/ \mathrm{ml}$, and 5 weeks was needed for full expression.

Preparation of brain slices. Horizontal slices containing the hippocampus, subicular complex, and entorhinal cortex were prepared 2-5 weeks after virus and/or tracer injection. Animals were anesthetized with ketamine hydrochloride and xylazine (100 and $15 \mathrm{mg} / \mathrm{kg}$, respectively). They were perfused through the heart with a solution of $125 \mathrm{NaCl}, 25$ sucrose, $2.5 \mathrm{KCl}, 25 \mathrm{NaHCO}_{3}, 1.25 \mathrm{NaH}_{2} \mathrm{PO}_{4}, 2.5 \mathrm{D}$-glucose, $0.1 \mathrm{CaCl}_{2}, 7$ $\mathrm{MgCl}_{2}$ (in mM) cooled to $4{ }^{\circ} \mathrm{C}$, and equilibrated with $5 \% \mathrm{CO}_{2}$ in $\mathrm{O}_{2}$. The brain was removed, and horizontal, 300 -to 320 - $\mu$ m-thick sections cut in the same solution with a vibratome (Leica VT1000S). They were stored for at least $1 \mathrm{~h}$ at $22^{\circ} \mathrm{C}-25^{\circ} \mathrm{C}$ in a chamber filled with ACSF containing the following (in mM): $124 \mathrm{NaCl}, 2.5 \mathrm{KCl}, 26 \mathrm{NaHCO}_{3}, 1 \mathrm{NaH}_{2} \mathrm{PO}_{4}, 2 \mathrm{CaCl}_{2}$, $2 \mathrm{MgCl}_{2}$, and $11 \mathrm{D}$-glucose, bubbled with $5 \% \mathrm{CO}_{2}$ in $\mathrm{O}_{2}, \mathrm{pH} 7.3$ (305-315 $\mathrm{mOsm} / \mathrm{L}$ ). Slices were then transferred to a recording chamber (volume 2-3 ml, temperature $33^{\circ} \mathrm{C}-35^{\circ} \mathrm{C}$ ) mounted on a BX51WI microscope (Olympus). Experiments were discontinued if transfection at the injection site was weak or if leakage had occurred. The dorsoventral level of horizontal slices that were used for recordings ranged from dorsoventral -2.6 to $-3.6 \mathrm{~mm}$ with respect to bregma (Fig. 1-1, available at https:// doi.org/10.1523/JNEUROSCI.0014-18.2018.f1-1), corresponding to the mid to dorsal portion of presubiculum (Paxinos and Franklin, 2013).

Whole-cell patch-clamp recordings. Recordings were made with glass pipettes pulled using a Brown-Flaming electrode puller (Sutter Instruments) from borosilicate glass of external diameter $1.5 \mathrm{~mm}$ (Clark Capillary Glass, Harvard Apparatus). Electrodes were filled with a solution containing the following (in mM): $135 \mathrm{~K}$-gluconate, $1.2 \mathrm{KCl}$, 10 HEPES, 0.2 EGTA, $2 \mathrm{MgCl}_{2}, 4 \mathrm{MgATP}, 0.4$ Tris-GTP, $10 \mathrm{Na}_{2}-$ phosphocreatine, and 2.7-7.1 biocytin. QX314 bromide (2 mm; Tocris Bioscience), a blocker of voltage-activated $\mathrm{Na}^{+}$channels, was added to the pipette solution when inhibitory (I) and excitatory (E) synaptic currents were measured at depolarized holding potentials (see Fig. 3). The $\mathrm{pH}$ of the pipette solution was adjusted to 7.3 with $\mathrm{KOH}$, and the osmolarity was $290 \mathrm{mOsm}$. Electrode resistance was 4-8 mOhm. Fluorescent PV or SST cells were identified using LED illumination with appropriate emission/excitation filters (OptoLED, Cairn Research) using a Luca CCD Camera (Andor). Whole-cell current-clamp recordings were made using a MultiClamp 700B amplifier and pCLAMP software (Molecular Devices). Membrane potential signals were filtered at $6 \mathrm{kHz}$ and digitized at $20-50 \mathrm{kHz}$. An estimated junction potential of $15 \mathrm{mV}$ was not corrected. PCs were identified as nonfluorescent regular-spiking neurons; PV- or SST-expressing interneurons were identified as red fluorescent cells in tissue from PvalbCre::tdTomato and Sst-Cre::tdTomato mice, respectively. Neuronal electrical properties were measured from hyperpolarizing and depolarizing step current injections and analyzed with Axograph X and routines written in MATLAB, as previously (Nassar et al., 2015) (Table 1). PV interneurons recorded from PvalbCre::tdTomato mice consistently fired action potentials (APs) with fast kinetics. We have suggested that labeled SST interneurons of Sst-Cre::tdTomato mice are heterogeneous (Nassar et al., 2015). This work was limited to labeled SST cells with a low threshold firing pattern. 
Table 1. Intrinsic properties of layer 3 presubicular neurons

\begin{tabular}{|c|c|c|c|c|c|c|c|c|c|c|c|c|}
\hline & \multicolumn{3}{|l|}{ PV } & \multicolumn{3}{|l|}{ SST } & \multicolumn{3}{|l|}{$P C$} & \multicolumn{3}{|l|}{$\mathrm{PC}$ beads ${ }^{+}$} \\
\hline & Mean & SEM & $N$ & Mean & SEM & $N$ & Mean & SEM & $N$ & Mean & SEM & $N$ \\
\hline Membrane potential (mV) & -67 & 1.10 & 13 & -54 & 2 & 15 & -72 & 3 & 17 & -74 & 1.1 & 15 \\
\hline Time constant (ms) & 19 & 3 & 10 & 38 & 8 & 10 & 28 & 6 & 8 & 27 & 4 & 11 \\
\hline Sag ratio & 1.10 & 0.01 & 12 & 1.20 & 0.02 & 15 & 1.04 & 0.01 & 16 & 1.05 & 0.01 & 16 \\
\hline Input resistance (m $\Omega$ ) & 147 & 12 & 13 & 438 & 58 & 14 & 362 & 68 & 15 & 359 & 34 & 14 \\
\hline Threshold current (pA) & 183 & 18 & 13 & 59 & 19 & 15 & 63 & 18 & 13 & 70 & 11 & 16 \\
\hline I-0 initial gain (Hz/pA) & 1.06 & 0.09 & 13 & 0.90 & 0.07 & 15 & 0.36 & 0.06 & 16 & 0.27 & 0.02 & 15 \\
\hline Firing frequency at $2 \times$ rheobase & 191 & 12 & 8 & 40 & 6.20 & 14 & 28 & 3.30 & 14 & 27 & 1.40 & 16 \\
\hline AP threshold (mV) & -39 & 1.20 & 13 & -34 & 0.90 & 15 & -38 & 0.80 & 17 & -30 & 0.60 & 16 \\
\hline AP amplitude (mV) & 77 & 1.10 & 13 & 76 & 1.80 & 15 & 81 & 1.03 & 17 & 80 & 1.40 & 16 \\
\hline AP half-duration (ms) & 0.20 & 0.01 & 13 & 0.30 & 0.01 & 15 & 0.60 & 0.01 & 17 & 0.65 & 0.02 & 16 \\
\hline AP maximum depolarization (V/s) & 624 & 22 & 13 & 507 & 23 & 15 & 478 & 17 & 17 & 452 & 22 & 16 \\
\hline AP maximum repolarization (V/s) & -464 & 22 & 13 & -272 & 14 & 15 & -127 & 4 & 17 & -121 & 4 & 16 \\
\hline
\end{tabular}

Optical stimulation. ChR2-expressing ATN axons were stimulated optically with either a single-wavelength LED system (470 nm; Cairn Research OptoLED) or laser illumination (405 nm; LuxX, Omicron), connected to the microscope via a custom-made triple port (Cairn Research). Synaptic responses of presubicular neurons, usually simultaneously recorded PCs and interneurons, were recorded in whole-cell current- or voltage-clamp modes. LED illumination gave a $200-\mu \mathrm{m}-$ diameter spot with a $60 \times 1.0 \mathrm{NA}$ plan-Apochromat objective (Fig. 2-1, available at https://doi.org/10.1523/JNEUROSCI.0014-18.2018.f2-1). Flashes of $0.5-20 \mathrm{~ms}$ were delivered close to recorded somata. We typically used low-intensity stimulation of $0.1-0.5 \mathrm{~mW}$, set to induce near threshold responses, reducing network activation after ATN axon stimulation (Fig. 2-2, available at https://doi.org/10.1523/JNEUROSCI.001418.2018.f2-2). Excitatory and inhibitory postsynaptic responses were evoked by $10 \mathrm{~Hz}$ and $30 \mathrm{~Hz}$ stimulus trains (light pulse duration, $0.5 \mathrm{~ms}$ ). We tested for monosynaptic excitation by stimulating in the presence of TTX ( $1 \mu \mathrm{m}$; Tocris Bioscience) to block polysynaptic excitation and 100 $\mu \mathrm{M}$ 4-AP (Sigma-Aldrich) to enhance axonal depolarization (Cruikshank et al., 2010; Mao et al., 2011). NBQX (10 $\mu \mathrm{M}$, Tocris Bioscience), D-AP5 (100 $\mu \mathrm{m}$, Tocris Bioscience), gabazine (10 $\mu \mathrm{M}$, Tocris Bioscience), and CGP 52432 (10 $\mu \mathrm{M}$, Tocris Bioscience) were used to block AMPA, NMDA, $\mathrm{GABA}_{\mathrm{A}}$, and $\mathrm{GABA}_{\mathrm{B}}$ receptors, respectively.

Inhibition of $\mathrm{PV}$ interneurons during photostimulation of the thalamic pathway was achieved by combining a yellow LED $(572 \mathrm{~nm})$ photoactivation of eNpHR3.0 in PV neurons, with a blue light (470 nm) illumination in the light path. Light intensity at the sample was set at 0.3 $\mathrm{mW}$. The yellow light pulse, of $20 \mathrm{~ms}$ duration, was triggered $5 \mathrm{~ms}$ before a blue light pulse of $0.5 \mathrm{~ms}$ duration so that $\mathrm{PV}$ interneurons were inhibited before and during thalamic axon stimulation. For each injected mouse, the efficacy of yellow LED-triggered hyperpolarization was verified in at least one PV interneuron.

The excitatory and inhibitory effects of stimulating thalamic fibers at different presubicular sites were explored in layer 3 PCs clamped to potentials between -30 and $0 \mathrm{mV}$. In this way, biphasic synaptic events could be detected as a focused $405 \mathrm{~nm}$ laser beam (LuxX, Omicron) was scanned over different presubicular sites (compare Fig. $3 F$ ). After acquiring an initial image with a $4 \times$ objective, we switched to a $60 \times$ objective for focal point illumination (spot size 5-10 $\mu \mathrm{m}$ ). A motorized platform (Luigs and Neumann) moved the stage across a scanning field as we explored a hexagonal grid of optical stimulation sites (Bendels et al., 2008; Beed et al., 2010) (custom software, Morgentau Solutions); 40-80 stimulation sites at $40 \mu \mathrm{m}$ separation were tested.

The spatial resolution of laser illumination is defined by the singlephoton illumination cone and diffraction limited by light scattering in the slice (Trigo et al., 2009). A light spot of $\sim 10-\mu \mathrm{m}$-diameter in $100 \mu \mathrm{M}$ pyranine (HPTS) solution was measured at the focus using the Luca CCD camera. The light was set to deliver $0.5-2 \mathrm{~ms}$ pulses at each stimulation site. Laser power was adjusted to $0.4-2 \mathrm{~mW}$, to record EPSC-IPSC sequences resulting from activation of few fibers. Grids were repeated three times for each recorded neuron.

We attempted to limit variability from differences in viral vector uptake/expression. First, records were made exclusively from slices where
ChR2-eYFP expression was visible at $4 \times$ magnification. Second, recordings were only made from superficial layer 3 where ChR2 expression was high. Third, we only used data from animals where significant excitatory responses were initiated in PCs in control conditions and after TTX/4-AP application. Finally, double-recordings from neighboring PCs and PV or SST interneurons let us normalize responses evoked in an interneuron to those induced by the same photo-stimulation in a nearby PC.

Data analysis. Peak amplitudes of averaged light-evoked PSCs $(n=30)$ were measured for PV and PCs. Failures and additional or later peaks were detected for EPSCs evoked in SST interneurons but not PV interneurons or PCs. We also measured the amplitude at the first peak of individual traces. Synaptic event amplitudes of $>3$ times the SD of the noise were considered to result from direct and/or disynaptic input(s). Success rate was determined as the number of detected EPSCs, divided by the total number of stimuli. EPSCs were recorded at holding potentials close to $-60 \mathrm{mV}$ and IPSCs near $0 \mathrm{mV}$. EPSC latency was calculated from the stimulus to $5 \%$ of the rising amplitude of the evoked current from individual traces and then averaged. Latency was measured to the first peak when multiple EPSC peaks were evoked. Short-term synaptic dynamics were analyzed by normalizing responses to each stimulus to the amplitude of the first event. IPSCs were recorded at $0 \mathrm{mV}$, in the presence of D-AP5, and were abolished by gabazine. IPSC onset was measured at $5 \%$ of the rising amplitude of the peak outward current. Onset jitter was defined as the SD of latencies to this 5\% amplitude point from repeated single sweeps. Paired-pulse ratio (PPR) was defined as the ratio of the amplitude of the second to the first postsynaptic response to dual stimuli. It was calculated from averages of responses to 10 stimuli. Postsynaptic responses were recorded at resting membrane potential in current clamp, except for SST interneurons, which were held at membrane potentials near $-50-55 \mathrm{mV}$ to suppress firing. AP latencies were calculated as the delay from stimulus onset to the peak of the AP. Spiking probability corresponded to the number of APs generated during a train of 10 stimulations for a given intensity, divided by 10 . Input resistance was monitored by small-current injection steps $(-50 \mathrm{pA})$. Recordings were discarded if changes exceeded $20 \%$.

Paired recordings. Whole-cell recordings of pairs of synaptically connected neurons were made in voltage-clamp mode. Depolarizing voltage injections (1-2 ms, 100-200 mV) were used to elicit single action currents in a presynaptic neuron. Unitary IPSCs were recorded at $-50 \mathrm{mV}$ and unitary EPSCs at $-70 \mathrm{mV}$ holding potential in the postsynaptic cell. EPSCs and IPSCs were automatically detected and measured from filtered records (low-pass 1-1.5 kHz) with a threshold of 4-6 pA for EPSCs and IPSCs. The properties of unitary IPSCs and EPSCs were determined from 30 to 60 traces. Peak amplitude was defined as the mean of all responses, including failures (amplitude close to $0 \mathrm{pA}$ ). Synaptic latency was estimated as the time between the peak of the presynaptic action current and $5 \%$ of the peak amplitude of a unitary IPSC. Rise time of synaptic currents was defined as the time from $20 \%$ to $80 \%$ of their peak amplitude. Synaptic event decay times were measured between peak and $50 \%$ of the peak. For analyses of short-term plasticity, PSCs in a train were normalized to the amplitude of the first EPSC or IPSC. Synaptic transfer rate was calculated as 

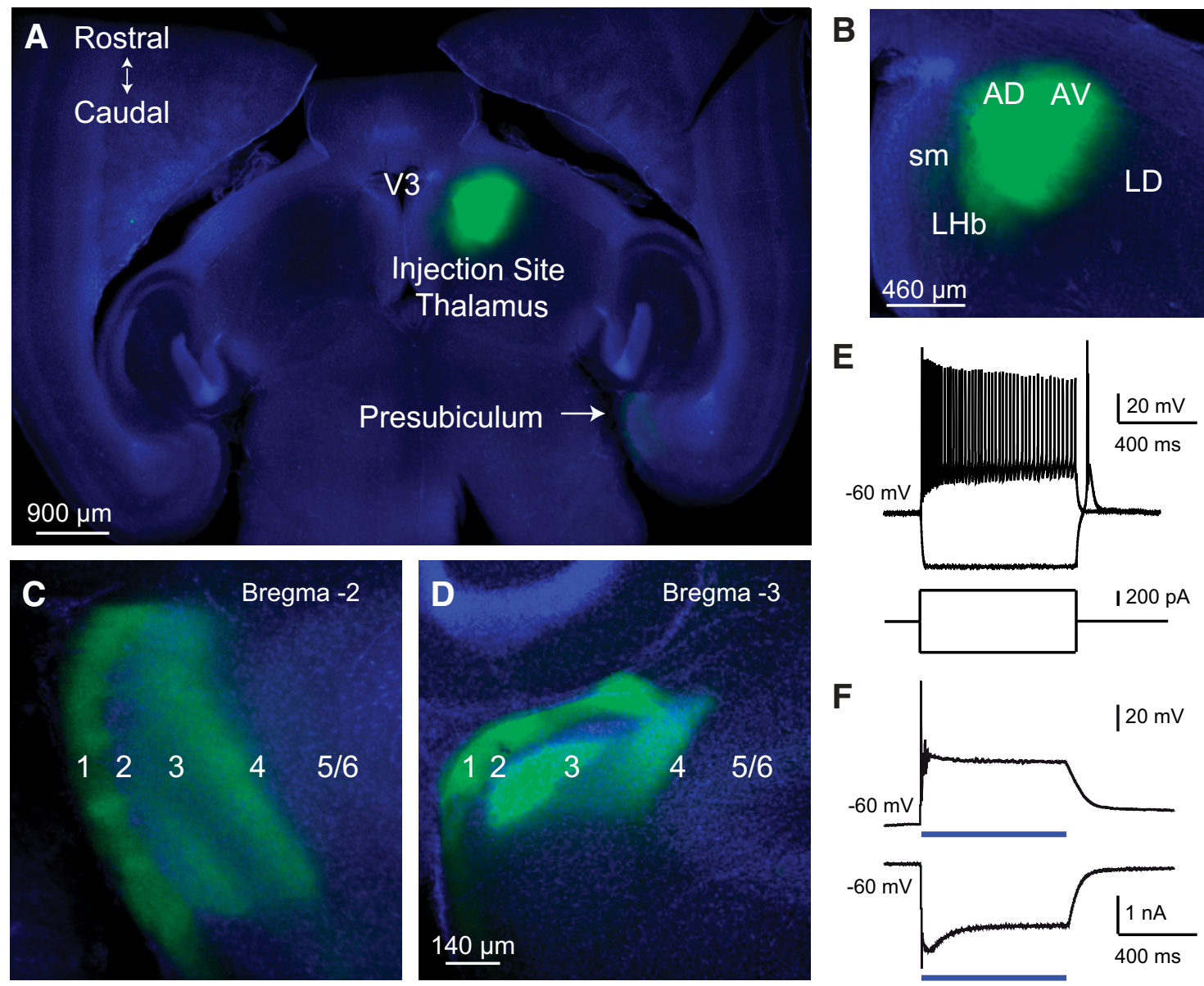

Figure 1. ChR2-eYFP expression in the ATN and in their axon terminals in the presubiculum. A, Mouse brain injected with AAV5-ChR2-eYFP (green) in the ATN. The 320- $\mu \mathrm{m}$-thick horizontal section with DAPI staining (blue). $\boldsymbol{B}$, ChR2-eYFP expression at the injection site. AD, Anterodorsal nucleus; AV, anteroventral nucleus; LD, laterodorsal nucleus; sm, stria medullaris; V3, third ventricle; $\mathrm{LHb}$, lateral habenula. $\boldsymbol{C}, \boldsymbol{D}, \mathrm{ChR2}$-eYFP-expressing axon terminals in the presubiculum at different dorsoventral levels, bregma -2 and $-3 \mathrm{~mm}$. Presubicular layers $1-6$ are indicated. More details about the presubicular anatomy, ChR2-eYFP expression patterns, and recording locations can be found Figure 1-1 (available at https://doi.org/10.1523/JNEUROSCI.0014-18.2018.f1-1) and Figure 1-2 (available at https://doi.org/10.1523/JNEUROSCI.0014-18.2018.f1-2). E, Firing of a thalamic cell induced by a twofold rheobase depolarizing current. Hyperpolarization induced by a negative current pulse is followed by a rebound burst. $\boldsymbol{F}$, Top, Blue light stimulation $(0.1 \mathrm{~mW}, 300 \mathrm{~ms})$ evoked spikes and depolarization block in the thalamic cell. Bottom, ChR2-mediated photocurrent recorded in voltage-clamp in response to the same photostimulation. Blue bar represents the light pulse. Recordings made in the presence of CNQX and D-AP5.

the number of detected postsynaptic events divided by the number of presynaptic spikes. Failure rate was 1 - transfer rate.

Image acquisition and analysis. Stained slices were visualized with a Retiga EXI camera (QImaging) and scanned with an Optigrid II (Thales Optem) on an inverted Olympus IX81 microscope to acquire structured images. Stacks of 50-80 images ( $z$ step, $0.7 \mu \mathrm{m})$ were acquired with an oil-immersion objective $(20 \times$, NA 0.9). Presubicular layers and borders were defined from cytoarchitectonic features defined from nuclear (DAPI) staining. Higher-resolution images (see Fig. $2 B$ ) were obtained using an Olympus FV-1000 confocal microscope to acquire $z$ stacks at $0.3 \mu \mathrm{m}$. Blue, green, and red fluorescent signals were acquired sequentially and images adjusted for contrast and brightness with ImageJ (National Institutes of Health).

Biocytin staining and morphological 3D reconstructions. Neurons were filled with $0.3 \%$ biocytin $(3 \mathrm{mg} / \mathrm{ml})$ during recordings to reveal their morphology post hoc (Simonnet et al., 2013; Nassar et al., 2015). After recording, slices were fixed in $4 \%$ PFA in $0.1 \mathrm{~m}$ phosphate buffer at $4^{\circ} \mathrm{C}$ for $24 \mathrm{~h}$. Slices were then rinsed in PBS and cryoprotected in $30 \%$ sucrose mixture at $4^{\circ} \mathrm{C}$ overnight. Membranes were permeabilized by three cycles of freeze-thawing over dry ice and then washed with PBS. Slices were agitated in saturation buffer containing $2 \%$ milk powder and $1 \%$ Triton $\mathrm{X}-100$ in PBS $0.1 \mathrm{M}$ for $3 \mathrm{~h}$ at room temperature. Then, sections were gently agitated with Streptavidin-Cy5 conjugate (1:500, Molecular Probes) and DAPI in the blocking solution overnight at $4^{\circ} \mathrm{C}$. After washing with PBS, slices were mounted on coverslips using ProLong Gold Antifade Mountant
(Invitrogen). Filled cells were visualized with a QImaging Retiga EXI camera on an inverted Olympus IX81 microscope. Structured images were acquired with an Optigrid system (Improvision) and Volocity software (PerkinElmer). Neuronal form was derived from $\mathrm{z}$ stacks of acquired images (Neurolucida, RRID:SCR_001775; MBF Bioscience).

Statistics. Signals were analyzed with AxoGraphX and custom-written software (Labview, National Instruments; MATLAB, The MathWorks). Algorithms to detect APs and measure active and passive neuronal properties are as described previously (Simonnet et al., 2013; Nassar et al., 2015). Results are given as mean \pm SEM ( $n=$ number of cells, slices, or animals as indicated). Statistical analysis was performed with Prism (GraphPad Software), MATLAB (The MathWorks), and R. The Wilcoxon signed rank test for matched pairs was used to compare nonparametric data in matched samples. A Kruskal-Wallis one-way ANOVA test was followed by Dunn's post hoc test to compare more than two groups. The Anderson-Darling two-sample procedure $(\alpha=0.05)$ was used to compare nonparametric data with different distributions. The Benjamini-Hochberg procedure was used to correct $p$ values for multiple testing. Significance levels are indicated as $p$ values.

\section{Results}

\section{Selective ChR2 expression in the ATN}

To study the functional connectivity of the ATN to the presubiculum, we made unilateral injections of AAV to express light- 

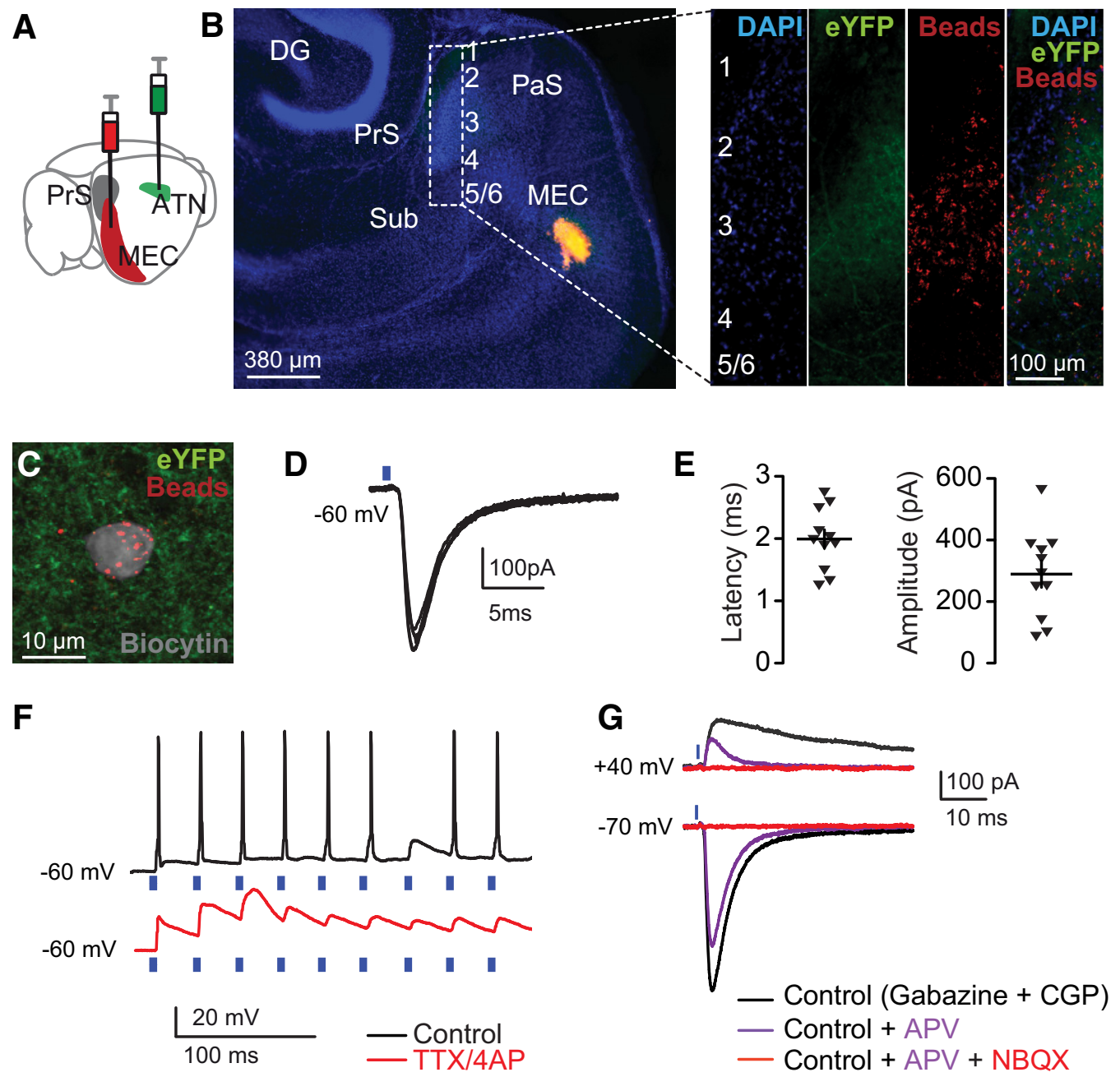

Figure 2. ATN axons contact MEC-projecting neurons. $\boldsymbol{A}$, Schematic showing unilateral injection sites for AAV5-ChR2 in ATN (green) and retrobeads in the MEC (red). $\boldsymbol{B}$, Left, Horizontal section of the parahippocampal formation with retrobeads injected in the MEC (orange). Blue represents DAPI staining. Thalamic axons expressing ChR2-eYFP target the presubiculum. DG, Dentate gyrus; PrS, presubiculum; Sub, subiculum; PaS, parasubiculum. Right, Magnification of the presubiculum ( $\boldsymbol{B}$, inset) stained with DAPI (blue), ChR2-eYFP-expressing thalamic axons (green), retrobeads (red), and a merged image (right). C, Confocal image of the soma of a biocytin-filled neuron in superficial layer 3 . The soma (gray) contains red retrobeads and is surrounded by thalamic axons (green). D, Light-evoked EPSCs in the same neuron. More details about the illumination area and calibration for the blue LED light can be found in Figure 2-1 (available at https://doi.org/10.1523/ JNEUROSCI.0014-18.2018.f2-1) and Figure 2-2 (available at https://doi.org/10.1523/JNEUROSCI.0014-18.2018.f2-2).E, Average EPSC latencies (left) and amplitudes (right) from 11 bead-labeled neurons. Horizontal and vertical lines indicate mean \pm SEM. F, Light stimuli repeated at $30 \mathrm{~Hz}$ initiated AP firing (top, black; same neuron as in C). TTX (1 $\mu \mathrm{M}$ ) and 4-AP (100 $\mu \mathrm{M})$ abolished spikes, whereas direct EPSPs persisted (bottom, red). G, Light-evoked currents at holding potentials of 40 and at $-70 \mathrm{mV}$ revealed glutamatergic EPSCs with a NMDA and AMPA receptor-mediated component. Recordings in the presence of $10 \mu \mathrm{m}$ gabazine and $10 \mu \mathrm{m}$ CGP 52432. EPSCs were entirely abolished by $100 \mu \mathrm{m}$ APV and $10 \mu \mathrm{m}$ NBQX.

gated Channelrhodopsin-2 fused to green fluorescent protein (ChR2-eYFP) in ATN neurons. After 2-3 weeks of incubation, horizontal slices were prepared, and the thalamic injection site was examined. Figure $1 A, B$ shows an example of ChR2-eYFP expression in the ATN. Labeled (eYFP) thalamic axons innervated layers 1 and 3 of the presubiculum more densely than layer 2 (Fig. 1-1, available at https://doi.org/10.1523/JNEUROSCI.001418.2018.f1-1; and Fig. 1-2, available at https://doi.org/10.1523/ JNEUROSCI.0014-18.2018.f1-2). Thalamic afferents did not project to deep presubicular layers, adjacent subiculum, or entorhinal cortex (Fig. 1C,D). Recording from ChR2-eYFPexpressing thalamic neurons in slices revealed typical rebound bursting (Fig. 1E). Illumination with blue light in the presence of the glutamatergic antagonists CNQX and D-AP5 depolarized these cells and induced firing in current-clamp records (Fig. $1 F$, top). In voltage-clamp mode, an inward ChR2-mediated photocurrent was detected (Fig. 1F, bottom). ChR2-eYFP-expressing thalamic neurons responded to light with latencies $<0.1 \mathrm{~ms}$ ( $n=$ 4 neurons from 2 mice).

\section{ATN axon terminals directly contact MEC-projecting pyramidal neurons}

We asked whether ATN axons innervate MEC-projecting PCs, by combining retrograde labeling of MEC-projecting cells in the presubiculum with the viral expression of ChR2-eYFP in thalamic axons (Fig. 2A,B). Red retrobeads were observed in neuronal somata located in the presubicular superficial layer and a few deeper neurons (Fig. 2B,C) (compare Huang et al., 2017), indicating that these project to the MEC. In ex vivo slice recordings, light stimulation of ATN axons induced EPSCs in all retrobead-labeled layer 3 neurons with somata surrounded by channelrhodopsin-expressing ATN axons (Fig. 2D, F, same neuron as in Fig. 2C; low-intensity LED stimulation, $0.1-0.5 \mathrm{~mW}$ ). The mean delay to EPSC onset was $2 \pm 0.15 \mathrm{~ms}(n=11$; Fig. $2 E)$, 
A

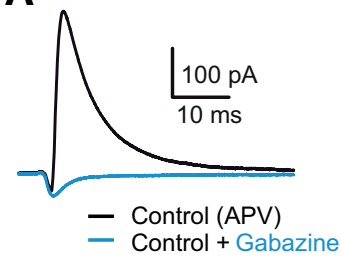

B

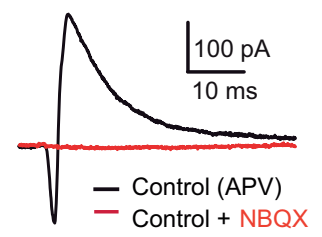

C
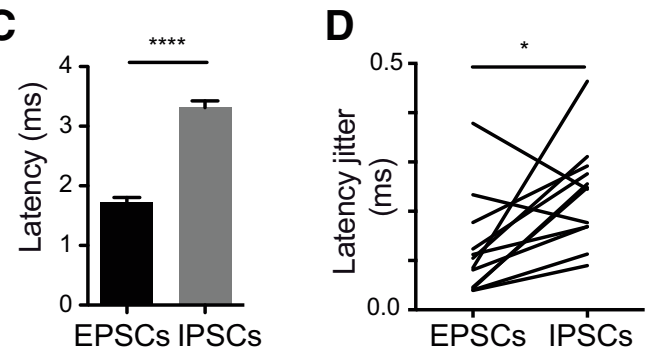

E

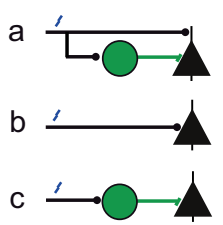

G

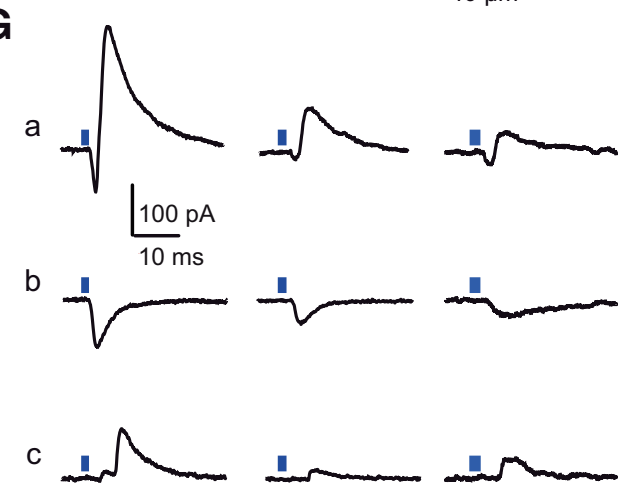

H

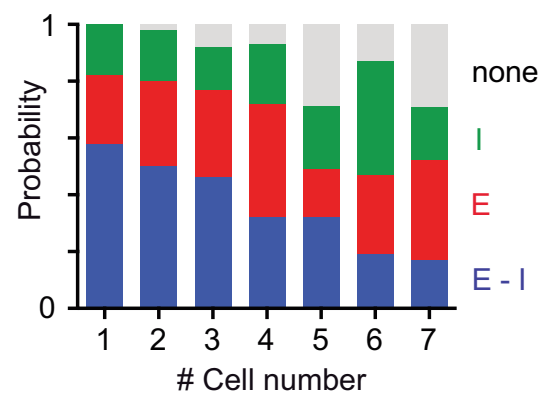

Figure 3. ATN-driven sequences of excitation-inhibition versus unbalanced excitation or inhibition. $\boldsymbol{A}, \boldsymbol{B}, \mathrm{ATN}$-evoked currents recorded from presubicular pyramidal neurons at $0 \mathrm{mV}$ holding potential, in the presence of APV. The current was biphasic, with an initial inward current followed by an outward current. $\boldsymbol{A}$, The outward current, mediated by $\mathrm{GABA}_{A}$ receptors, was entirely blocked by gabazine. $B, N B Q X$ abolished both the inward current and the disynaptic GABAergic component. C, D, Disynaptic IPSCs induced by ATN stimuli have longer-onset latencies and more jitter than the ATN-driven EPSCS. Wilcoxon matched-pairs signed rank test: ${ }^{*} p<$ $0.05 ;{ }^{* * * *} p<0.001$. Data are mean \pm SEM. $\boldsymbol{E}$, Different possibilities of afferent connectivity: a pyramidal neuron may receive $(\boldsymbol{E} \boldsymbol{a})$ excitation and feedforward inhibition, $(\boldsymbol{E} \boldsymbol{b})$ excitation only, or (Ec) inhibition only. $\boldsymbol{F}$, Schematic of the experiment showing the presubiculum (PrS) with the recording pipette and the PC soma (red), and the grid of laser light stimulation compatible with monosynaptic activation. Evoked EPSC amplitudes varied for different neurons in different slices $(289 \pm 43 \mathrm{pA}$, $n=11$ neurons from 5 animals; Fig. $2 E$ ). In current-clamp recordings, ATN fiber stimulation initiated APs in bead-labeled MEC-projecting neurons at resting membrane potential (Fig. 2F; stimulations repeated at $30 \mathrm{~Hz}$ ). APs were abolished by TTX (1 $\mu \mathrm{M})$ and 4-AP $(100 \mu \mathrm{M})$, but light stimuli continued to induce EPSPs, indicating that postsynaptic cells were contacted directly by synapses of ChR2-expressing ATN axons $(n=11)$ (compare Mao et al., 2011). EPSCs were suppressed by bath application of AMPA and NMDA receptor antagonists (Fig. $2 G ; n=3$ neurons from three retrobead-labeled mice). The glutamatergic nature of thalamic excitation was confirmed in four additional layer 3 pyramidal neurons from three mice that had not received retrobead injections.

\section{Activation of ATN inputs drives an excitation/inhibition sequence in the presubiculum}

When presubicular layer 3 pyramidal neurons were voltageclamped at $0 \mathrm{mV}$, photostimulation of ChR2-expressing thalamic fibers initiated biphasic synaptic currents. (Fig. $3 A, B$ ). An initial excitatory inward current (EPSC) was rapidly followed by an inhibitory outward current (IPSC). Following whole-field LED stimulation, both EPSCs and IPSCs were elicited in all layer 3 pyramidal neurons tested ( $n=9$ PCs from 4 animals), including retrobead-labeled MEC-projecting PCs $(n=3$ PCs from 3 animals). IPSCs were abolished by both the GABA receptor antagonist gabazine and the AMPA receptor antagonist NBQX (Fig. $3 A, B$ ). IPSC onset latencies were significantly longer (Fig. $3 C$; $3.3 \pm 0.1 \mathrm{~ms} ; n=12$ from 5 animals; $p<0.0001$, Wilcoxon signed rank test) than those of the EPSCs $(1.7 \pm 0.1 \mathrm{~ms} ; n=12$ from 5 animals). In PCs, the delay between EPSC and IPSC onset was $1.6 \pm 0.1 \mathrm{~ms}$. Onset latency jitter for EPSCs was significantly less than that of IPSCs (EPSCs, $0.12 \pm 0.03 \mathrm{~ms}$; IPSCs, $0.23 \pm$ $0.03 \mathrm{~ms} ; n=12$ cells from 5 animals; $p<0.05$, Wilcoxon signedrank test; Fig. 3D). These data show that photostimulation of ATN afferents can evoke a direct glutamatergic excitation followed by a disynaptic inhibition, compatible with thalamic-induced feedforward inhibition of layer 3 presubicular PCs (Fig. 3E, top).

We next asked whether synaptic excitation is followed by inhibition, when few ATN fibers are stimulated to mimic sparse in vivo head directional inputs. Rather than a wide-field stimulation, we used a focused blue laser to stimulate small sets of ATN fibers. Layer 3 PCs were recorded in voltage clamp at $-30 \mathrm{mV}$, to separate excitatory and inhibitory synaptic current components, and low-intensity laser scanning photostimulation was randomly applied to different sites across the presubiculum (Fig. 3E-G). Laser stimuli often initiated an inward current followed by an outward current, similar to sequences evoked by whole-field LED stimuli (Fig. $3 G a$ ). This was the case, especially for stimulation sites close to the soma of recorded layer 3 PCs. Amplitudes of both inward and outward currents tended to be higher when stimulating in close proximity to the soma, probably due to the activation of a greater number of thalamic fibers that make synaptic contacts. However, laser stimulation could also evoke either

sites (black circles, spacing $40 \mu \mathrm{m}$ ). PaS, Parasubiculum; Sub, subiculum. Ga, Sequences of excitatory-inhibitory responses. $\mathbf{G} \boldsymbol{b}$, Excitatory responses only. Gc, Inhibitory responses only. Recordings from the same pyramidal neuron for different laser light stimulation sites across the presubiculum. $\boldsymbol{H}$, Probability to elicit excitatory-inhibitory responses (E-I, blue), excitatory responses only (E, red), or disynaptic inhibitory responses only (I, green). Gray represents no response. 

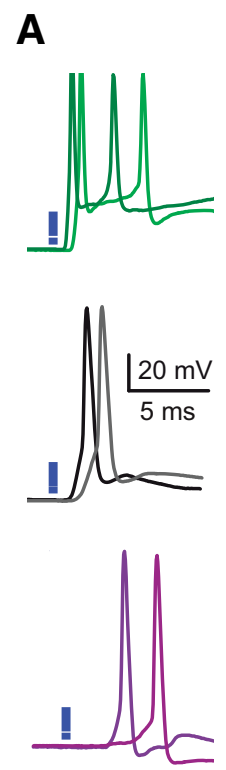
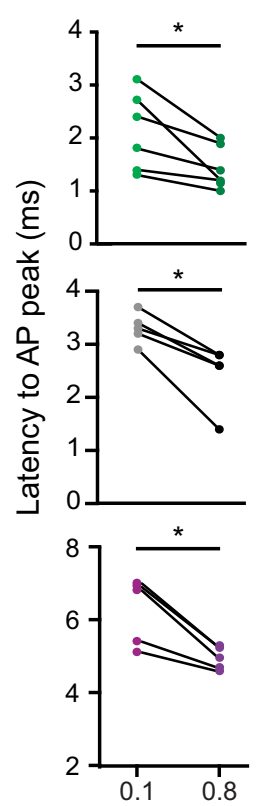

Power Intensity (mW)

D
B
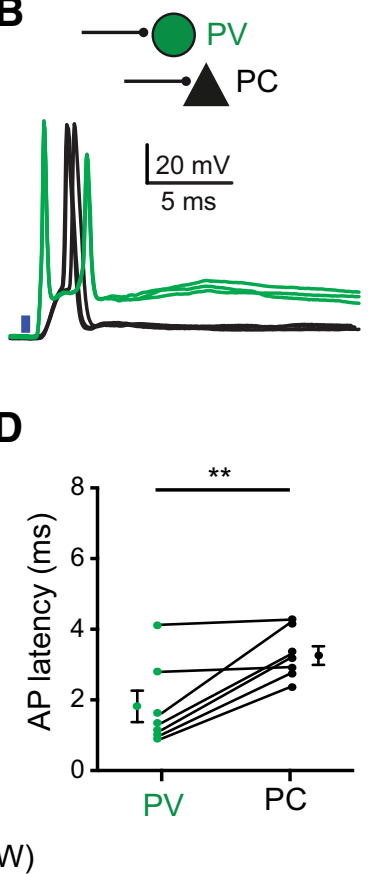

C
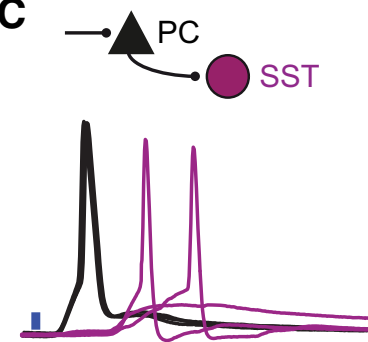

E

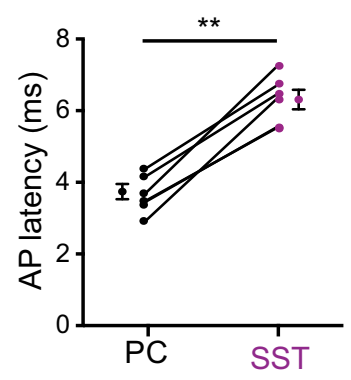

Figure 4. Relative AP timing in pairs of pyramidal neurons and interneurons. A, Left, Current-clamp recording of a PV interneuron (green), a PC (black), and SST interneuron (purple), with two different light intensities for stimulation of ATN axon terminals ( 0.2 and $1.1 \mathrm{~mW})$. Right, Summary data. Higher stimulus intensities led to shorter AP latencies in the same neuron. $\boldsymbol{B}$, APs initiated by light activation of thalamic fibers in a simultaneously recorded PC-PV pair or (C) in a PC-SST pair. D, E, AP latencies from 7 PC-PV pairs, and from 6 PC-SST pairs. Each dot represents 1 neuron. AP latencies in PC cells were longer than in PV interneurons but shorter than in SST interneurons. Wilcoxon matched-pairs signed rank test: ${ }^{*} p<0.05$; ${ }^{* *} p<0.01$.

only inward (Fig. 3Gb) or only outward currents (Fig. 3Gc). Outward currents were abolished by gabazine ( $10 \mu \mathrm{M}, n=3$ of 3 tested cells) confirming their GABAergic nature, and both inward and outward currents were suppressed by glutamate receptor antagonists (NBQX, $10 \mu \mathrm{M}$; APV, $100 \mu \mathrm{M}$ ). Overall, for all stimulus sites tested, the probability to evoke sequences of EPSCs and IPSCs was $36 \pm 6 \%$ ( $n=7$ neurons from 3 mice), the probability of initiating only an EPSC was $29 \pm 3 \%$ and that for initiating exclusively an IPSC was $22 \pm 3 \%$. For low-intensity laser light stimulation of thalamic fibers at different stimulation sites, $13 \pm$ $4 \%$ sites did not evoke any synaptic responses in PCs (Fig. $3 H$ ). Sparse activation of ATN inputs therefore often, but not always, induces sequential excitatory and inhibitory synaptic events.

\section{AP timing in PCs and interneurons}

We next compared the timing of firing induced in presubicular PCs and PV- and SST-expressing interneurons by ATN stimulation to ask how the two types of interneuron contribute to disynaptic feedforward inhibition (Fig. 4). AP latency varied with light intensity: higher-intensity stimulation recruited more ATN fibers and induced significantly shorter AP latencies (6 PV interneurons [green] from 3 mice; 5 PCs [black] from 4 mice; 5 SST interneurons [purple] from 3 mice; $p<0.05$, Wilcoxon matchedpairs signed rank test; Figure $4 A$ ). In subsequent experiments, light intensity was reduced to the minimum value at which APs were still initiated in simultaneously recorded PC-PV or PC-SST neuron pairs. In PC-PV pairs, the latency to the first AP was always shorter for PV interneurons than for PCs $(3.26 \pm 0.26 \mathrm{~ms}$; $\mathrm{PV}, 1.84 \pm 0.44 \mathrm{~ms} ; n=7$ pairs from 4 mice, $p<0.01$, Wilcoxon matched-pairs signed rank test; Fig. $4 B, D$ ). In contrast, in PCSST pairs, PCs always fired before SST interneurons (latencies: PC, $3.68 \pm 0.22 \mathrm{~ms}$; SST, $6.2 \pm 0.27 \mathrm{~ms} ; n=6$ pairs from 4 mice, $p<0.01$, Wilcoxon matched-pairs signed rank test; Fig. $4 C, E)$.
These data suggest that PV, but not SST interneurons, may mediate thalamic feedforward inhibition.

\section{ATN provides direct excitatory inputs to pyramidal neurons and PV interneurons but not to SST interneurons}

We next compared responses of presubicular PCs, fast-spiking $\mathrm{PV}$ interneurons, and low-threshold spiking SST interneurons to photostimulation of ATN fibers. Pyramidal neuron-interneuron pairs were recorded in presubicular layer 3 in Pvalb-Cre::tdTomato or Sst-Cre::tdTomato transgenic mice (Fig. 5A-F) (compare Nassar et al., 2015). Intrinsic electrophysiological properties of both recorded cells were characterized from hyperpolarizing and depolarizing current pulses (Table 1). Optical stimulation of ATN inputs was adjusted to elicit synaptic excitation in at least one neuron of the recorded pair.

Amplitudes of EPSCs in PV interneurons were significantly larger than those of EPSCs in PCs (PV, $800 \pm 109 \mathrm{pA}, n=10$ neurons from 5 animals; $\mathrm{PC}, 178 \pm 55 \mathrm{pA}, n=10$ neurons from 5 mice; $p<0.001$, Wilcoxon matched-pairs signed rank test; Fig. $5 A-C, G)$. In contrast, the amplitudes of EPSCs in SST interneurons were significantly smaller than those recorded simultaneously in PCs ( $306 \pm 41 \mathrm{pA}$; SST, $58 \pm 17 \mathrm{pA} ; n=11$ neurons from 10 mice; $p<0.001$ Wilcoxon matched-pairs signed rank test; Fig. $5 D-G)$. EPSC onset latencies were similar in PV cells and PCs (PV, $2.0 \pm 0.1 \mathrm{~ms} ; \mathrm{PC}, 2.4 \pm 0.1 \mathrm{~ms} ; n=10$ neurons from 5 animals; Fig. $5 H$ ), but significantly longer in SST cells (PC, $2.0 \pm$ $0.2 \mathrm{~ms}$; SST, $5.3 \pm 0.4 \mathrm{~ms} ; n=11$ recordings from 10 animals, $p<$ 0.001, Wilcoxon matched-pairs signed rank test; Fig. $5 H$ ). Light stimulation of ATN axons reliably evoked EPSCs in all PCs and PV interneurons, but not in SST interneurons. Although SST cells responded at least once to repeated trials, failures occurred with a $30 \%$ probability across trials (success rate, $0.70 \pm 0.06 ; n=$ 11 neurons from 6 animals; Fig. $5 I$,J; $p<0.0001$, Kruskal-Wallis 

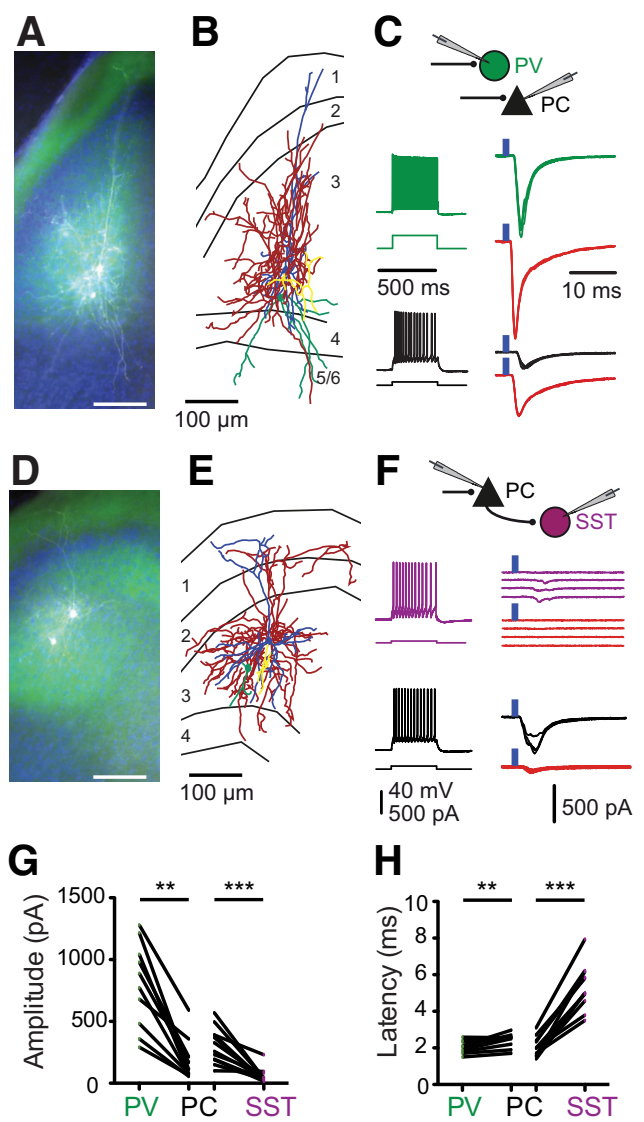

H
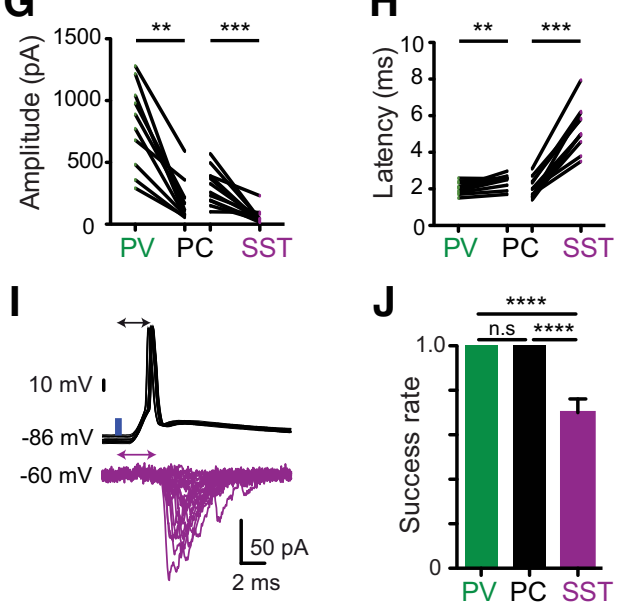

Figure 5. Long-range excitatory inputs from ATN to pairs of PV or SST interneurons and pyramidal neurons in layer 3. A, D, Presubicular slice with two biocytin-filled neurons. $\boldsymbol{A}, \boldsymbol{B}$, Pyramidal neuron and PV interneuron. $\boldsymbol{D}, \boldsymbol{E}$, Pyramidal neuron and SST interneuron. Green represents ATN axons in the superficial layers. Scale bars, $100 \mu \mathrm{m} . \boldsymbol{B}, \boldsymbol{E}$, Reconstructed cell pairs. Blue represents $P C$ dendrites. Yellow represents $P C$ axons. Green represents interneuron dendrites. Red represents interneuron axons. $C$, Dual records of PV interneuron (green) and pyramidal neuron (black) or $(\boldsymbol{F})$, SST interneuron (purple) and pyramidal neuron (black) respectively. Left, Firing pattern in response to a twofold rheobase current injection. Right, Light-evoked EPSCs from the illustrated pair of simultaneously recorded pyramidal neuron and interneuron. Red represents the presence of TTX $(1 \mu \mathrm{m})$ and 4-AP $(100 \mu \mathrm{m})$ in the bath solution. Amplitudes $(\boldsymbol{G})$ and latencies $(\boldsymbol{H})$ from double-recorded principal neuron and interneuron EPSCS. Wilcoxon matched-pairs signed rank test: ${ }^{* *} p<0.01$; ${ }^{* * *} p<0.001$. I, Light stimulation reliably generated APs in a PC. EPSCs in a simultaneously recorded SST interneuron had a $30 \%$ failure rate (30 trials). J, Bar plots of success rate for synaptic events in different cell types: calculated from 30 trials for each neuron tested; 13 PV interneurons (green), 13 PC (black), and 11 SST interneurons (purple). ${ }^{* * *} p<0.0001$ (Kruskal-Wallis and Dunn's multiplecomparison post hoc test). Data are mean $\pm \mathrm{SEM}$.

and Dunn's multiple-comparison post hoc test). These results were obtained in conditions where presynaptic APs evoked synaptic events. Evidence for direct monosynaptic inputs to pyramidal neurons and PV interneurons was confirmed by showing that synaptic responses persisted during TTX and 4-AP perfusion (1 $\mu \mathrm{M}$ TTX and $100 \mu \mathrm{M}$ 4-AP; $n=5$ pairs from 5 animals; Fig. $5 C$, red traces). However, evoked responses in SST interneurons were abolished after perfusion of TTX and 4-AP (Fig. 5F, red traces), compatible with an indirect recruitment of SST neurons, following thalamic PC activation. Thus, ATN fibers directly excite pyramidal neurons and PV interneurons but not SST interneurons. PV cells therefore appear well suited to mediate thalamic feedforward inhibition onto PC cells.

\section{Presubicular PV interneurons are highly interconnected with pyramidal neurons}

We next examined interactions between PV interneurons and layer 3 PCs in double recordings from synaptically connected cell pairs $(n=40)$. Figure 6 shows typical morphologies and synaptic interactions of a reciprocally connected PV-PC pair. Action currents initiated in PV cells elicited IPSCs of monosynaptic latencies $(0.68 \pm 0.03 \mathrm{~ms}, n=19$; Table 2$)$ in the PC (Fig. $6 B ; n=20$ of 40 tested pairs. Conversely, PC action currents initiated unitary EPSCs with monosynaptic latencies $(0.74 \pm 0.03 \mathrm{~ms}, n=17$, Table $2 ; n=21$ of 40 tested pairs). Synaptic interactions between PV interneurons and PCs were often reciprocal ( $n=15$ of 40 tested pairs; Fig. $6 B$ ), suggesting that a high portion of PV cells mediate both feedforward and feedback inhibition. IPSCs had rapid kinetics consistent with inhibitory synapses terminating on perisomatic sites on PCs. The rise time of unitary IPSCs was $0.52 \pm 0.07 \mathrm{~ms}(n=19)$. The rise time of unitary EPSCs from PC-to-PV cells was $0.31 \pm 0.02 \mathrm{~ms}(n=17)$. The mean amplitude of EPSCs induced in PV cells was $73 \pm 20 \mathrm{pA}(n=17$; Fig. $6 C, E)$, and their mean decay time constant was $0.91 \pm 0.07 \mathrm{~ms}(n=17)$. The mean amplitude of IPSCs elicited in PCs was $14 \pm 2 \mathrm{pA}(n=$ 19; Fig. $6 C, E)$, and their mean decay time constant was $2.90 \pm$ $0.20 \mathrm{~ms}(n=19)$. The transfer rate, or probability that a postsynaptic event was induced, was $0.79 \pm 0.06$ for EPSCs $(n=17)$ and $0.71 \pm 0.07$ for IPSCs $(n=19)$. During $50 \mathrm{~Hz}$ trains of action currents initiated in PCs or in interneurons (Fig. 6D-F), EPSC amplitudes became moderately depressed (PPR, $0.82 \pm 0.07, n=$ 15 ) as were those of IPSCs (paired pulse ratio, $0.85 \pm 0.03, n=$ 18). We conclude that layer 3 presubicular PV cells mediate a widespread inhibition of local PCs.

\section{ATN fibers induce PV interneuron-mediated feedforward inhibition in the presubiculum}

These data show that ATN axons excite both presubicular layer 3 PV interneurons and MEC-projecting PCs (Figs. 2-5), and that these two cell types are highly interconnected (Fig. 6). We next asked whether PV cells mediate a thalamic feedforward inhibition. To do so, AAV.hSyn.hChR2-eYFP was injected into the ATN and AAV.Ef1a.DIO.eNpHR3.0-eYFP into the presubiculum of Pvalb-Cre mice. This double optogenetic strategy let us test the effect of inhibiting presubicular PV cells on synaptic responses induced in PCs by ATN fiber stimulation (Fig. 7A). Expression of the light-gated, chloride-pumping halorhodopsin (eNpHR3.0) hyperpolarized presubicular PV interneurons in response to yellow light (Fig. $7 B ; n=5$ cells from 3 animals). In cell-attached recordings, PV cells fired in response to blue light stimulation of ATN fibers, and firing was inhibited during concomitant activation of eNpHR3.0 (Fig. 7C). In voltage-clamp recordings from layer 3 pyramidal neurons, ATN stimulation induced a sequence of inward (EPSC) and outward (IPSC) currents at $0 \mathrm{mV}$. Yellow light silencing of PV interneurons dramatically, and reversibly, reduced the feedforward inhibitory current $(n=8$ PCs from 3 mice, $p<0.01$, Kruskal-Wallis and Dunn's multiplecomparison post hoc test) (Fig. $7 D, E)$. As a control, we noted that the peak amplitude of ATN-driven EPSCs was unchanged during yellow light stimulation ( $-60 \mathrm{mV}$; light off/light on/light off, $n=8$ cells 
A

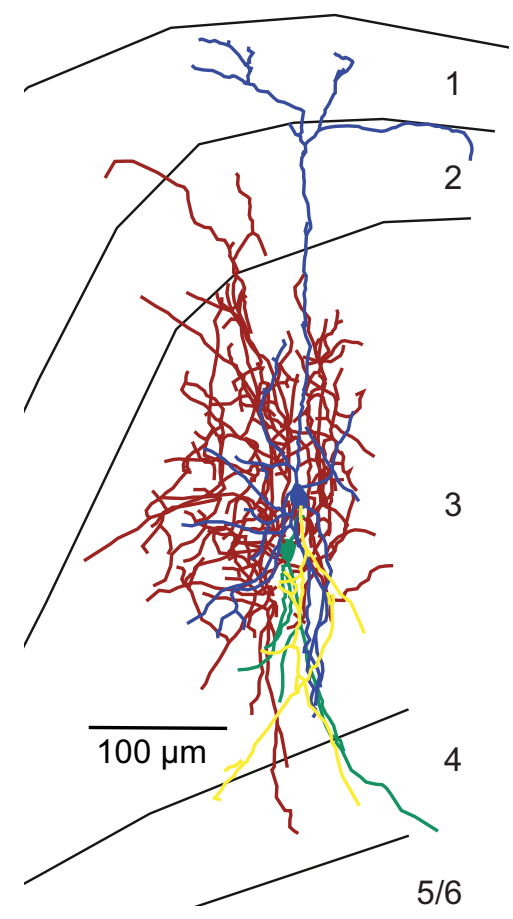

B

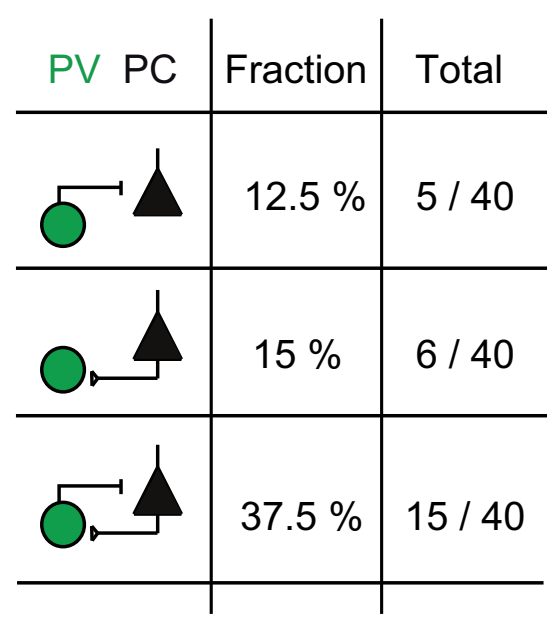

C

PC

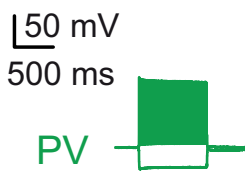
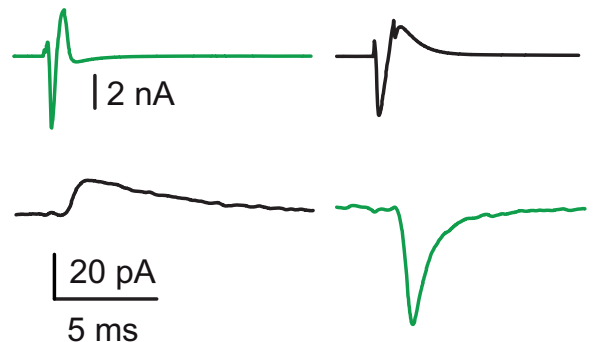

D

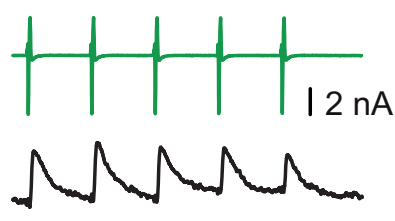

$\frac{10 \mathrm{pA}}{20 \mathrm{~ms}}$
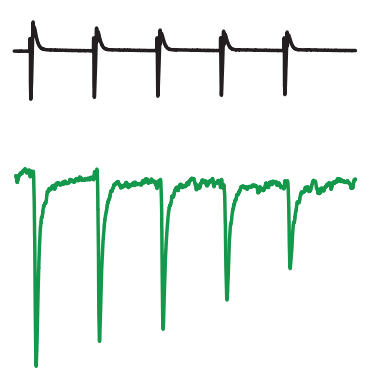

E

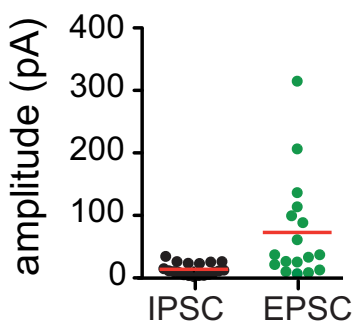

$\mathbf{F}$

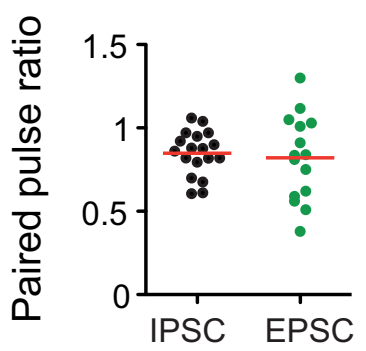

Figure 6. Presubicular layer 3 PV interneurons and PCs are highly interconnected. $A$, Anatomical reconstruction of a pair of reciprocally connected PV interneuron and pyramidal neuron in presubicular layer 3. Blue represents PC dendrites. Yellow represents PC axons. Green represents PV dendrites. Red represents PV axons. Left, Subiculum. Right, Parasubiculum. $\boldsymbol{B}$, Summary of connectivity between PV and PC cells. C, Paired recording of PV-PC pair shown above. Left, Firing patterns in response to a negative and positive (twofold rheobase) current injection. An evoked action current in the PV cell (green, $-70 \mathrm{mV}$, voltage clamp) initiated a short-latency IPSC in the PC (black, $-50 \mathrm{mV}$, voltage clamp). Conversely, an evoked action current in the PC elicited an EPSC in the PV cell. Traces are averaged from 10 trials. D, Unitary IPSCs (black) and EPSCs (green) from the same cell pair induced by 5 action currents at $50 \mathrm{~Hz}$. Absolute amplitudes (E) and PPR ( $\boldsymbol{F}$ ) of IPSCS in PC neurons (black) and EPSCs in PV interneurons (green). Each dot represents averaged recordings from one neuron.

Table 2. EPSC and IPSC properties from synaptically connected PV interneuronpyramidal neuron pairs

\begin{tabular}{|c|c|c|c|c|c|c|}
\hline & \multicolumn{3}{|l|}{ EPSCS } & \multicolumn{3}{|l|}{ IPSCS } \\
\hline & Mean & SEM & $N$ & Mean & SEM & $N$ \\
\hline Rise time (ms) & 0.31 & 0.02 & 17 & 0.52 & 0.07 & 19 \\
\hline Decay time (ms) & 0.91 & 0.07 & 17 & 2.90 & 0.20 & 19 \\
\hline Latency onset (ms) & 0.74 & 0.03 & 17 & 0.68 & 0.03 & 19 \\
\hline Transfer rate & 0.79 & 0.06 & 17 & 0.71 & 0.07 & 19 \\
\hline
\end{tabular}

from 3 animals, Kruskal-Wallis and Dunn's multiple-comparison post hoc test; Fig. $7 F$ ). These data show that PV interneurons mediate a thalamic feedforward inhibition of layer 3 PCs.

\section{Effects of repetitive activation of ATN inputs depend on} postsynaptic cell identity

We then investigated the dynamics of EPSC responses to repetitive, low-intensity (0.1- $0.5 \mathrm{~mW})$ stimulation of ATN fibers at 10 or $30 \mathrm{~Hz}$. In PV and PC neurons, the amplitude of light-evoked 
EPSCs was reduced during trains of 10 stimuli at either 10 or $30 \mathrm{~Hz}$ (Fig. $8 A-F$ ). EPSCs in PV interneurons depressed more rapidly and more strongly (PPR, 10 $\mathrm{Hz}, 0.63 \pm 0.03 ; 30 \mathrm{~Hz}, 0.58 \pm 0.04$, $n=12$; significant depression of EPSC amplitudes after the third stimulus; Anderson-Darling and Hochberg-Benjamini multiple-comparison test) than those in pyramidal neurons (PPR, $10 \mathrm{~Hz}: 0.93 \pm$ 0.04, $n=26 ; 30 \mathrm{~Hz}: 0.96 \pm 0.05, n=25$; significant depression after the sixth stimulus; Fig. 8C,F). In contrast, we observed a transient, short-term facilitation of disynaptic EPSCs in SST interneurons. During stimulus trains at $30 \mathrm{~Hz}$, EPSC amplitude increased significantly between the first and the second and third stimulus (PPR, $30 \mathrm{~Hz}: 5.3 \pm 1.19, n=15$; Fig. $8 H, I)$. Repetitive stimulation at $10 \mathrm{~Hz}$ induced very small or no facilitation in SST interneurons (PPR, $10 \mathrm{~Hz}: 1.56 \pm 0.32$, $n=14$; Fig. $8 G, I)$. These data indicate distinct synapse dynamics for different cell types. Dynamic depression of EPSCs in PV cells should weaken feedforward inhibition of PCs and facilitate firing during maintained head direction signals from the ATN.

\section{Dynamics of spiking probability for pyramidal neurons and interneurons} How do differences in synaptic input dynamics affect firing in excitatory and inhibitory presubicular neurons? We examined the evolution of spiking probability during repetitive stimuli. AP firing probability was first determined over a range of light intensities (Fig. 7A). In PV interneurons, small increases in light intensity rapidly led to a spiking probability of 1. At higher intensities, single light pulses could initiate more than one AP, thus producing firing probabilities $>1$, for 12 of 13 PV cells tested (Fig. 9A). Overall, the probability of AP discharge was much lower for pyramidal neurons and SST interneurons, for both $10 \mathrm{~Hz}$ (PC, $0.5 \pm 0.1, n=22$; SST, $0.3 \pm 0.1, n=15)$ and 30 Hz stimulations (PC, $0.5 \pm 0.1, n=22$; SST, $0.4 \pm 0.1, n=14$ ) than for PV interneurons $(10 \mathrm{~Hz}, 1.5 \pm 0.1, n=13$; $30 \mathrm{~Hz}, 1.4 \pm$ $0.1, n=11)$. Most PC and SST neurons did not sustain firing until the 10th pulse in a train, even for the higher light intensities.

We next compared the dynamics of firing during repetitive ATN fiber stimuli of intermediate light intensities $(0.2-1 \mathrm{~mW})$. These stimuli evoked at least one AP but with probability of firing $<100 \%$ to each pulse. The probability to initiate PV interneuron firing was highest for the first pulse of both $10 \mathrm{~Hz}$ ( $n=16$ neurons from 7 animals) and $30 \mathrm{~Hz}$ trains $(n=18$ neurons from 7 animals) (Fig. 9B,E). The spiking probability was then quickly and significantly reduced for the second pulse and during the remainder of the train $(p<0.0001$, Anderson-Darling test and Hochberg-Benjamini multiple-comparison test; Fig. 9E). The dynamics of firing in PCs differed. At $10 \mathrm{~Hz}$, spiking probability was highest for the first pulse, whereas it was highest for the yellow light stimuli.
B

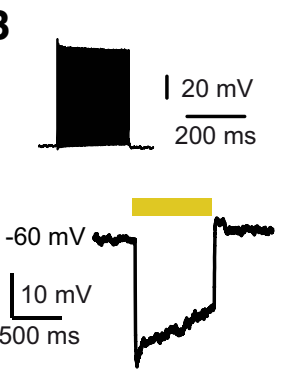

C

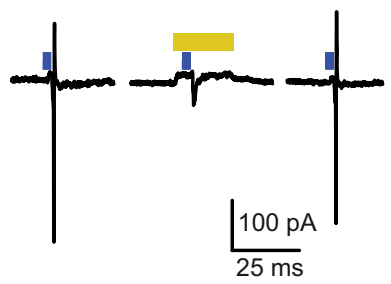

$25 \mathrm{~ms}$
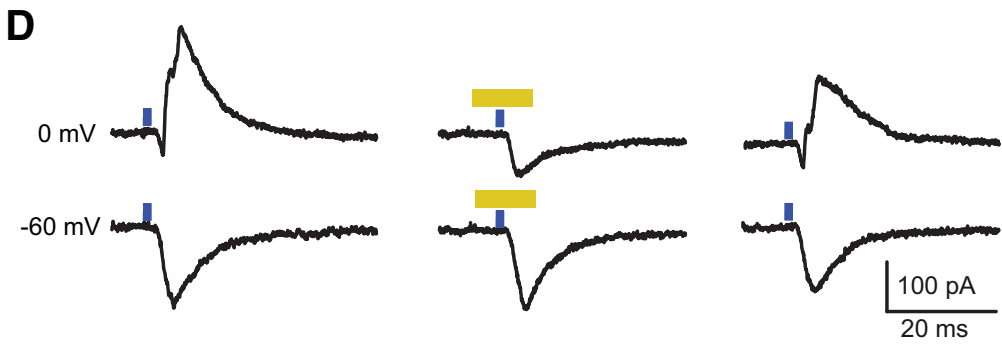

$\mathbf{E}$

$\mathbf{F}$

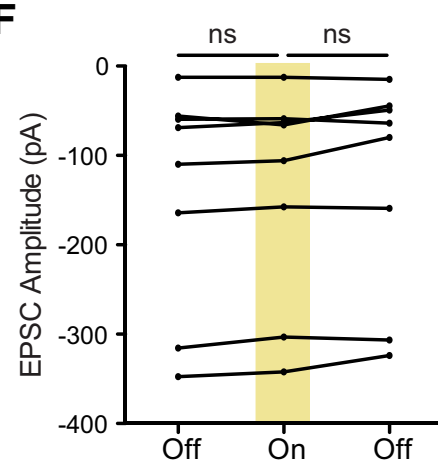

Figure 7. PV interneurons mediate ATN-driven feedforward inhibition in the presubiculum. $\boldsymbol{A}$, Blue ( $470 \mathrm{~nm})$ and yellow (585 $\mathrm{nm}$ ) illumination via the same light path was used to activate $\mathrm{ChR2}$ alone, or in combination with eNpHR. $\boldsymbol{B}, \mathrm{A}$ depolarizing current ATN inputs with blue light, before, during, and after illumination with yellow light. Yellow light was triggered $5 \mathrm{~ms}$ before the

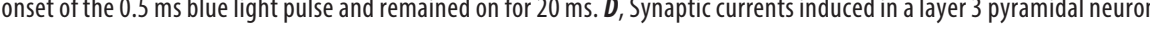
photostimulation (blue) of ATN fibers in the absence, in the presence, and again in the absence of yellow light. Yellow (middle) reversibly inhibited PV interneurons and suppressed evoked IPSCs recorded as outward currents at 0 Dunn's multiple-comparison post hoc test). F, EPSC recorded in P( cells at $-60 \mathrm{mV}$ holding potential were not affected by

second pulse at $30 \mathrm{~Hz}(\mathrm{PC}, n=23$ neurons from 10 animals, statistical significance, $p<0.01$; Fig. 9C,F). After the fourth pulse, and for the remainder of $10 \mathrm{~Hz}$ and $30 \mathrm{~Hz}$ trains, spiking probability was less than for the first pulse (Fig. 9 E, F). Pyramidal neurons and, to a greater extent, SST interneurons did not always fire at the first pulse of stimulus trains. In SST cells, we detected a tendency for spiking facilitation for the second pulse for $10 \mathrm{~Hz}$ stimulation (SST, $n=18$ neurons from 7 animals), and an initial, significant facilitation for $30 \mathrm{~Hz}$ stimulation (SST, $n=17$ neurons from 6 animals; $p<0.001$, AndersonDarling test and Hochberg-Benjamini multiple-comparison test; Fig. 9D, G).

These data reveal a strong initial recruitment of PV interneurons by ATN inputs, which depresses during maintained stimuli. Disynaptically induced firing in SST cells is shaped by facilitating dynamics of the PC-SST synapse and a moderately decreasing probability of PC firing. For stimulations repeated at $30 \mathrm{~Hz}$, the summation of EPSPs together with and depression of feedfor- 
A
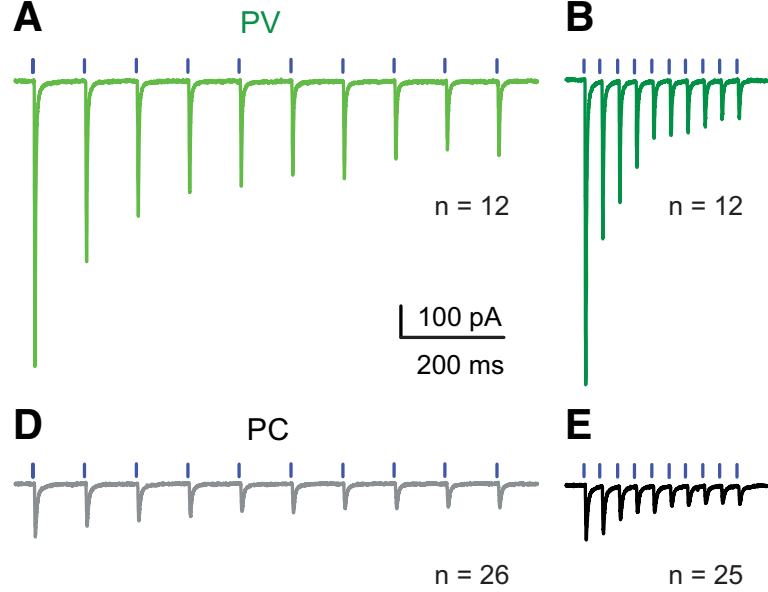
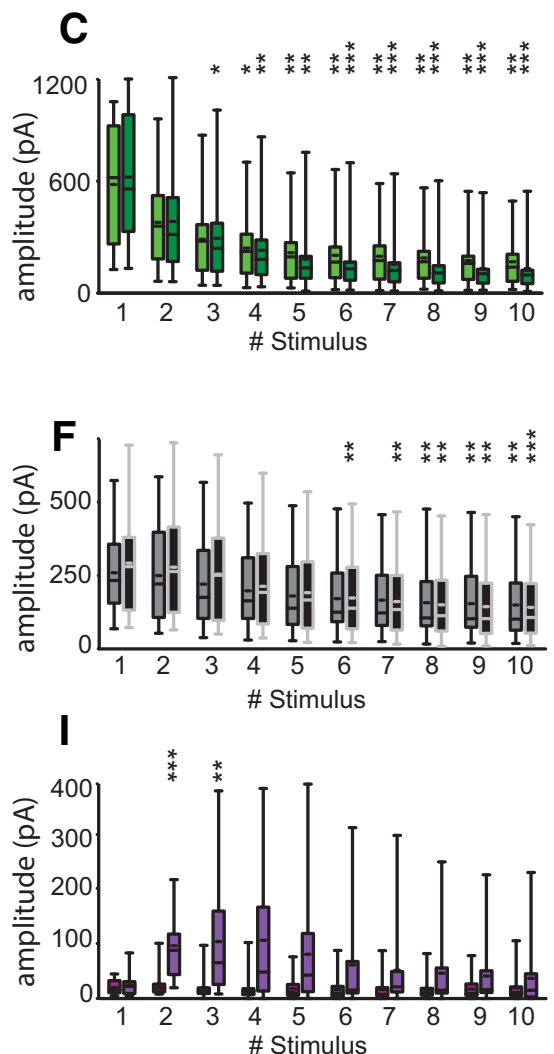

Figure 8. Synaptic dynamics of responses to photostimulation of ATN inputs in layer 3 pyramidal neurons and interneurons. $\boldsymbol{A}, \mathbf{D}, \mathbf{G}$, EPSCs evoked by 10 successive light stimuli repeated at $10 \mathrm{~Hz}$, and $(\boldsymbol{B}, \boldsymbol{E}, \boldsymbol{H})$ at $30 \mathrm{~Hz}$ in PV interneurons (light green, dark green), PC cells (gray, black), and SST interneurons (purple, violet). $\boldsymbol{C}, \boldsymbol{F}, \boldsymbol{I}$, EPSC amplitudes to stimuli at $10 \mathrm{~Hz}$ and $30 \mathrm{~Hz}$ for the three cell types, respectively. Box plots represent minimum, maximum, lower and upper quartiles, median, and mean values. Anderson-Darling test and Hochberg-Benjamini multiple-comparison test: ${ }^{*} p<0.05 ;{ }^{* *} p<0.01 ;{ }^{* * *} p<0.001$.

ward inhibition may lead to a highest PC spiking probability on the second pulse. We note that thalamic neurons anticipate head direction signals by 25-40 ms (Blair and Sharp, 1995; Taube and Muller, 1998), whereas presubicular neurons signal the current direction. Possibly, the fast, transient feedforward inhibition mediated via PV interneurons helps transform anticipatory direction signals of the thalamus into a real-time head direction signal in presubiculum.

\section{Discussion}

Here we show that glutamatergic synaptic inputs to the presubiculum from the ATN excite PCs and PV interneurons, which mediate disynaptic feedforward inhibition. PV interneurons are recruited at low-stimulus intensities by synapses with depressing dynamics. Controlled by inhibitory circuits that are most effective at stimulus onset, PC firing increases transiently during repetitive stimulation, even though ATN fiber-mediated excitation of principal cells also follows depressing dynamics. In contrast to PV cells, SST interneurons were excited indirectly via pathways that facilitated during repetitive stimulation and so mediate a delayed inhibition during repetitive ATN activity. We showed that activating different sets of ATN fibers in a slice did not always evoke an inhibitory response and that PV interneurons could mediate a lateral inhibition of principal neurons that were not directly excited.

\section{Optical activation of long-range axon terminals with $\mathrm{ChR} 2$}

The presubiculum is innervated by thalamus, subiculum, parasubiculum, retrosplenial, visual, and entorhinal cortex (van
Groen and Wyss, 1990a,b,c; van Groen and Wyss, 1992; Jones and Witter, 2007; Sugar et al., 2011). Here we optically activated thalamic afferents after injecting an AAV-ChR2-eYFP construct in the ATN. Paired recordings of interneurons and PCs let us define local connectivity and compare the strength and dynamics of ATN inputs.

Synaptic dynamics derived by optical stimulation of ChR2containing axons should be interpreted with caution (Cruikshank et al., 2010). We took several measures to avoid artifacts. A mutated version of ChR2 with reduced calcium permeability (Lin et al., 2009: Nagel et al., 2003) was used to avoid Ca-dependent effects on transmitter release and synaptic dynamics (Neher and Sakaba, 2008). Synaptic depression may be artifactually enhanced according to AAV serotype. Responses determined with AAV9-mediated ChR2 expression are comparable with those induced by electrical stimuli (Jackman et al., 2014). Our data showed that both AAV5 and AAV9 serotypes were associated with short-term depression in principal neurons and PV interneurons. Facilitating dynamics of repetitive stimuli in SST interneurons reflect distinct properties of the PC-SST synapse after PC firing. Data obtained by optical stimuli apparently reflect distinct responses of principal neurons, PV and SST interneurons.

\section{Anterior thalamic afferents excite presubicular layer 3 PCs and interneurons}

Layer 3 presubicular head direction cells project to the MEC (van Groen and Wyss, 1990c; Honda and Ishizuka, 2004; PrestonFerrer et al., 2016). We showed that ATN inputs induced large 
A

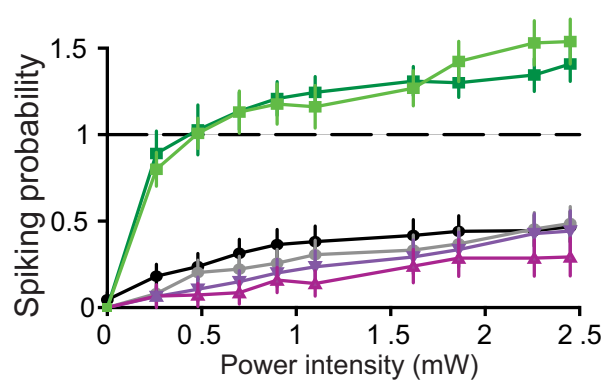

B

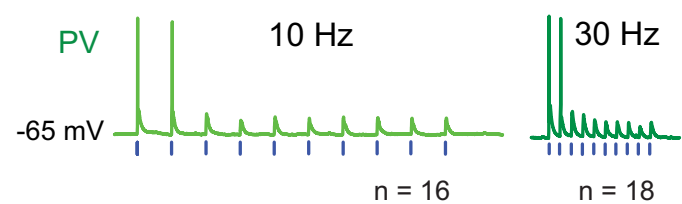

C $\mathrm{PC}$

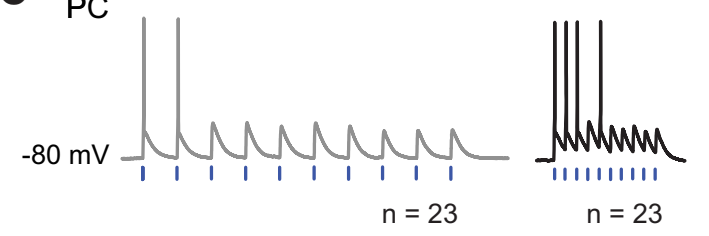

D SST

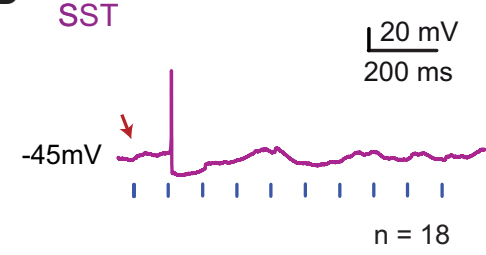

$\mathbf{E}$

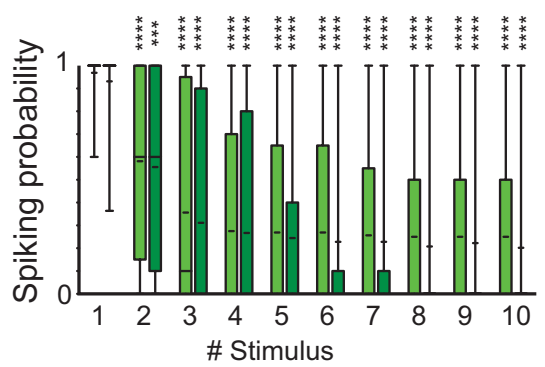

$\mathbf{F}$

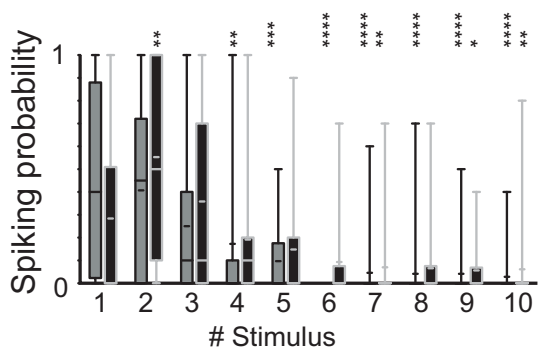

G

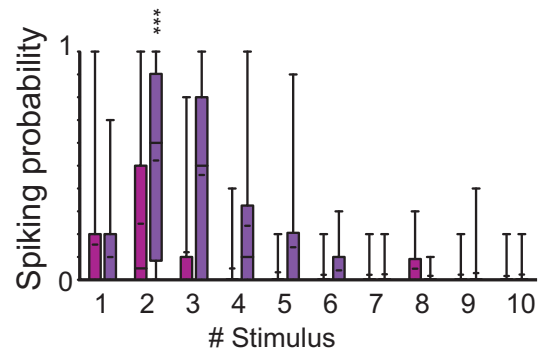

Figure 9. Cell type-specific spiking probabilities following optical stimulation of ChR2-expressing ATN fibers. A, Variation of spiking probability as a function of light intensity. A spiking probability of 1 corresponds to 10 spikes for a train of 10 stimuli. At higher intensities, a single pulse sometimes induced multiple spikes in PV interneurons (green). Black represents PC neurons. Purple represents SST interneurons. Data are mean \pm SEM. Examples of responses of a PV interneuron $(\boldsymbol{B})$, pyramidal neuron $(\boldsymbol{C})$, and SST interneuron $(\boldsymbol{D})$ to $10 \mathrm{~Hz}$ and $30 \mathrm{~Hz}$ stimulation at resting potential or near AP threshold. D, Red arrow indicates the absence of a spike for the first pulse. $E-G$, AP spiking probabilities for each cell type for $10 \mathrm{~Hz}$ and $30 \mathrm{~Hz}$ represented by box plots showing the lower and upper quartiles, the median, and the mean. Anderson-Darling test and Hochberg-Benjamini multiple-comparison test, to compare the spiking probability of each pulse to the first pulse: ${ }^{*} p<0.05$; ${ }^{* *} p<0.01 ;{ }^{* * *} p<0.001 ;{ }^{* * * *} p<0.0001$.

EPSPs at short latencies in these cells. Intrinsic electrophysiological properties of labeled MEC-projecting neurons were similar to those of unlabeled local PCs (Table 1). Stimulating ATN fibers at $10 \mathrm{~Hz}$ induced PC firing, which diminished during a train. Stimulation at $30 \mathrm{~Hz}$, in contrast, revealed a high-pass filtering where firing probability increased transiently, before a sustained reduction.

PV interneurons of layer 3 were also directly excited by thalamic fibers. EPSC latencies in PV interneurons and PCs were short and similar to those of monosynaptic thalamic inputs to barrel cortex (Cruikshank et al., 2010) and other longrange excitatory cortical inputs (Lee et al., 2013; Keshavarzi et al., 2014; Haley et al., 2016). Latencies were somewhat shorter in PV interneurons than in PCs (Fig. 5), possibly due to distinct subcellular sites of

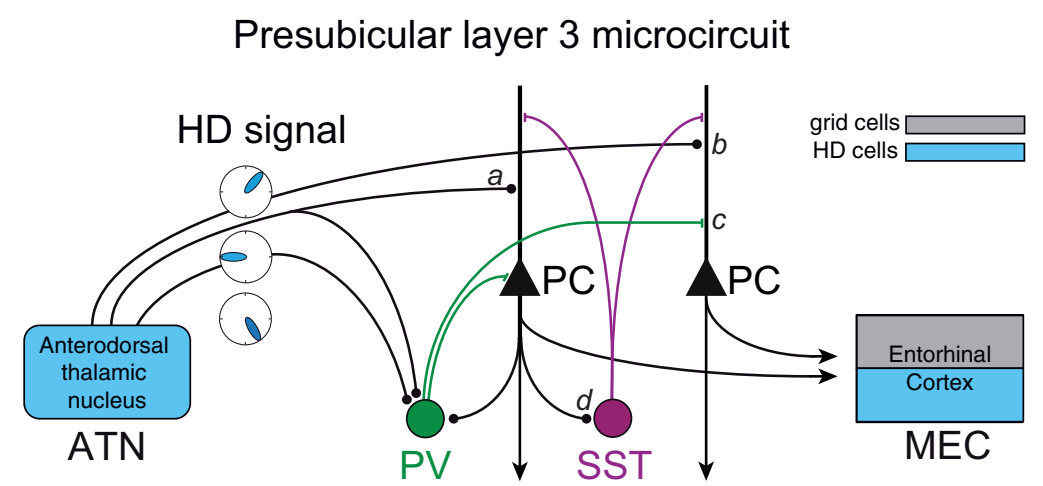

Figure 10. Schematic illustration of connectivity of ATN fibers targeting presubicular layer 3 neurons. Presubicular PCs projecting to $\mathrm{MEC}$ receive direct excitation from thalamic fibers. PV-expressing interneurons also receive direct excitation from thalamic fibers, and they provide transient feedforward inhibition onto $P C$. The activation of single thalamic fibers may either lead to (a) PC excitation followed by feedforward inhibition, or (b) only excitation, or (c) only rapid disynaptic inhibition of PCs (compare Fig. 3). SST interneurons (d) are recruited in a feedback manner following AP discharge of local PCs (Fig. 4) at high frequency (Fig. 9). SST-PC connectivity is high (compare Simonnet et al., 2017) and provides activitydependent feedback or lateral inhibition. 
excitatory synapses. ATN afferents may innervate the soma of PV cells, whereas thalamic fibers innervate dendritic spines at some distance from PC somata.

In SST interneurons, light-evoked synaptic responses were smaller, with longer latencies and transmission failed frequently. SST interneurons were less likely to fire than PV cells, even though their intrinsic excitability and input resistance are higher and resting potential is more depolarized (Table 1). SST cells were excited disynaptically via layer 3 PCs because EPSCs were suppressed by TTX and 4-AP (Figs. 5; Fig. 10) (Simonnet et al., 2017). In somatosensory cortex, too, circuits for the excitation of PV cells are functionally stronger that those that excite SST interneurons (Cruikshank et al., 2010; Lee et al., 2013).

\section{Thalamic excitation may be fine-tuned by PV-mediated inhibition}

Optical stimulation of ATN fibers induced EPSC-IPSC sequences in layer 3 PCs. IPSC onset latency was short (Fig. 3), as for other thalamocortical pathways (Pouille and Scanziani, 2001; Gabernet et al., 2005; Cruikshank et al., 2010; Stokes and Isaacson, 2010). Our data suggest that feedforward inhibition was largely mediated by presubicular PV interneurons. PV cells fire rapidly when thalamic fibers are stimulated (Figs. 4; 5) and contact local PCs with high probability (Fig. 6). Presubicular PV cells innervated 20 of 40 PCs tested, similar to the connectivity of fast-spiking PV cells in somatosensory or visual cortex (Holmgren et al., 2003; Yoshimura and Callaway, 2005). Reciprocal connectivity in the feedback inhibitory circuit was high (Holmgren et al., 2003; Yoshimura and Callaway, 2005; Yoshimura et al., 2005; Packer and Yuste, 2011). Further, optical activation of halorhodopsin let us demonstrate the essential role of PV interneurons in disynaptic feedforward inhibition (Fig. 7). Silencing presubicular PV interneurons largely suppressed disynaptic inhibition in pyramidal neurons. PV cells thus mediate a fast, reliable feedforward control of ATN signals (Fig. 10).

Feedforward inhibition seems likely to increase with the number of active afferents (Isaacson and Scanziani, 2011). This point was demonstrated by comparing whole-field optical and focal laser stimulation of ChR2-expressing ATN fibers. Whole-field stimuli induced balanced EPSC-IPSC sequences in PCs; but in responses to a sparser fiber activation induced by focal stimuli (Fig. 3), EPSCs were not succeeded by IPSCs for 20\%-30\% of presubicular sites tested. Possibly inhibition mediated by distal dendritic synapses may have been underestimated due to insufficient space clamp (Williams and Mitchell, 2008; Kubota et al., 2015). Indeed, it is difficult to compare dendritic excitation and inhibition without making assumptions on the site and strength of contacts (Chadderton et al., 2014). Nevertheless, our data reveal a variable somatic balance of excitation and inhibition, which presumably affects synaptic integration and AP initiation (Markram et al., 2004). We also noted in all cells that disynaptic IPSCs were induced with no preceding EPSC from some stimulation sites. PV interneurons with widespread axonal arbors may thus mediate both feedforward and lateral disynaptic presubicular inhibition (Fig. 10).

\section{Hypothesis for functional implications for presubicular HD signal processing}

Presubicular layer 3 is a crucial node in head direction signal transmission from the ATN to MEC. Inputs to the presubiculum probably possess direction tuning (Taube, 2007; Peyrache et al., 2015). The feedforward excitatory-inhibitory microcircuits of layer 3 may sharpen head direction signals relayed to the entorhi- nal grid cell system (Tukker et al., 2015; Winter et al., 2015; Preston-Ferrer et al., 2016). As for inhibitory circuits of auditory cortex (Wu et al., 2008; Chadderton et al., 2014), head direction cells coding for nonpreferred directions may receive inhibitory, but not excitatory, inputs. As in barrel cortex, direction-dependent shifts in timing of excitation and inhibition may result in a "window of opportunity" for excitatory inputs to induce firing (Wilent and Contreras, 2005).

Fast-spiking interneurons in vivo show higher firing rates during rotation (Preston-Ferrer et al., 2016). Our in vitro data show thalamic excitation of PV cells depresses during repetitive thalamic activity (Fig. 8). These observations fit together: During a head turn, active thalamic afferent fibers change rapidly, so that thalamic excitation and firing of PV cells should be maintained. The depressing dynamics of PV cell excitation could thus permit the "reconstruction" of angular velocity signals by decoding thalamic head directional inputs.

During immobility, when a same set of thalamic fibers is repeatedly active in vivo, synaptic excitation of PV cells may become depressed, as in our in vitro experiments (Fig. 8). Feedforward inhibition weakens as PV cells fire less and the excitatory-inhibitory balance may become shifted to excitation (Whitmire and Stanley, 2016) if synaptic depression is greater for inhibition than for excitation, as in barrel cortex (Gabernet et al., 2005). The depressing dynamics of the ATN-PV synapse may favor delayed PC recruitment (on the second pulse for $30 \mathrm{~Hz}$ stimulation in vitro; Fig. 9). Thus, PV interneuron circuit properties permit both finetuning of changing ATN inputs and a differential treatment of persistent ATN inputs.

SST interneurons are more effectively excited during persistent activation, due to facilitating synaptic dynamics (Ma et al., 2010). We showed previously that SST cell activity during maintained head direction may enhance PC firing through precisely timed feedback inhibition during PC spike repolarization (Simonnet et al., 2017). We suggest that presubicular circuits switch between two regimens according to the angular velocity of head movements. During immobility, SST-PC interactions may support maintained HD firing by attractor-like mechanisms (Simonnet et al., 2017). During head turns, in contrast, PV-mediated inhibition may fine-tune the HD signal transmitted to MEC.

\section{References}

Amaral DG, Witter MP (1989) The three-dimensional organization of the hippocampal formation: a review of anatomical data. Neuroscience 31: 571-591. CrossRef Medline

Bassett JP, Tullman ML, Taube JS (2007) Lesions of the tegmentomammillary circuit in the head direction system disrupt the head direction signal in the anterior thalamus. J Neurosci 27:7564-7577. CrossRef Medline

Beed P, Bendels MH, Wiegand HF, Leibold C, Johenning FW, Schmitz D (2010) Analysis of excitatory microcircuitry in the medial entorhinal cortex reveals cell-type-specific differences. Neuron 68:1059-1066. CrossRef Medline

Bendels MH, Beed P, Leibold C, Schmitz D, Johenning FW (2008) A novel control software that improves the experimental workflow of scanning photostimulation experiments. J Neurosci Methods 175:44-57. CrossRef Medline

Blair HT, Sharp PE (1995) Anticipatory head direction signals in anterior thalamus: evidence for a thalamocortical circuit that integrates angular head motion to compute head direction. J Neurosci 15:6260-6270. CrossRef Medline

Boccara CN, Sargolini F, Thoresen VH, Solstad T, Witter MP, Moser EI, Moser MB (2010) Grid cells in pre- and parasubiculum. Nat Neurosci 13:987-994. CrossRef Medline

Chadderton P, Schaefer AT, Williams SR, Margrie TW (2014) Sensoryevoked synaptic integration in cerebellar and cerebral cortical neurons. Nat Rev Neurosci 15:71-83. CrossRef Medline 
Cruikshank SJ, Urabe H, Nurmikko AV, Connors BW (2010) Pathwayspecific feedforward circuits between thalamus and neocortex revealed by selective optical stimulation of axons. Neuron 65:230-245. CrossRef Medline

Gabernet L, Jadhav SP, Feldman DE, Carandini M, Scanziani M (2005) Somatosensory integration controlled by dynamic thalamocortical feedforward inhibition. Neuron 48:315-327. CrossRef Medline

Goodridge JP, Taube JS (1997) Interaction between the postsubiculum and anterior thalamus in the generation of head direction cell activity. J Neurosci 17:9315-9330. CrossRef Medline

Haley MS, Fontanini A, Maffei A (2016) Laminar- and target-specific amygdalar inputs in rat primary gustatory cortex. J Neurosci 36:2623-2637. CrossRef Medline

Hippenmeyer S, Vrieseling E, Sigrist M, Portmann T, Laengle C, Ladle DR, Arber S (2005) A developmental switch in the response of DRG neurons to ETS transcription factor signaling. PLoS Biol. 3:e159. CrossRef Medline

Holmgren C, Harkany T, Svennenfors B, Zilberter Y (2003) Pyramidal cell communication within local networks in layer $2 / 3$ of rat neocortex. J Physiol 551:139-153. CrossRef Medline

Honda Y, Ishizuka N (2004) Organization of connectivity of the rat presubiculum: I. Efferent projections to the medial entorhinal cortex. J Comp Neurol 473:463-484. CrossRef Medline

Huang LW, Simonnet J, Nassar M, Richevaux L, Lofredi R, Fricker D (2017) Laminar localization and projection-specific properties of presubicular neurons targeting the lateral mammillary nucleus, thalamus or medial entorhinal cortex. eNeuro 4:ENEURO.0370-16.2017. CrossRef

Isaacson JS, Scanziani M (2011) How inhibition shapes cortical activity. Neuron 72:231-243. CrossRef Medline

Jackman SL, Beneduce BM, Drew IR, Regehr WG (2014) Achieving highfrequency optical control of synaptic transmission. J Neurosci 34:77047714. CrossRef Medline

Jones BF, Witter MP (2007) Cingulate cortex projections to the parahippocampal region and hippocampal formation in the rat. Hippocampus 17:957-976. CrossRef Medline

Keshavarzi S, Sullivan RK, Ianno DJ, Sah P (2014) Functional properties and projections of neurons in the medial amygdala. J Neurosci 34:86998715. CrossRef Medline

Kubota Y, Kondo S, Nomura M, Hatada S, Yamaguchi N, Mohamed AA, Karube F, Lübke J, Kawaguchi Y (2015) Functional effects of distinct innervation styles of pyramidal cells by fast-spiking cortical interneurons. eLife 4:07919. CrossRef Medline

Langston RF, Ainge JA, Couey JJ, Canto CB, Bjerknes TL, Witter MP, Moser EI, Moser MB (2010) Development of the spatial representation system in the rat. Science 328:1576-1580. CrossRef Medline

Lee S, Kruglikov I, Huang ZJ, Fishell G, Rudy B (2013) A disinhibitory circuit mediates motor integration in the somatosensory cortex. Nat Neurosci 16:1662-1670. CrossRef Medline

Lin JY, Lin MZ, Steinbach P, Tsien RY (2009) Characterization of engineered channelrhodopsin variants with improved properties and kinetics. Biophys J 96:1803-1814. CrossRef Medline

Ma WP, Liu BH, Li YT, Huang ZJ, Zhang LI, Tao HW (2010) Visual representations by cortical somatostatin inhibitory neurons: selective but with weak and delayed responses. J Neurosci 30:14371-14379. CrossRef Medline

Madisen L, Zwingman TA, Sunkin SM, Oh SW, Zariwala HA, Gu H, Ng LL, Palmiter RD, Hawrylycz MJ, Jones AR, Lein ES, Zeng H (2010) A robust and high-throughput Cre reporting and characterization system for the whole mouse brain. Nat Neurosci 13:133-140. CrossRef Medline

Mao T, Kusefoglu D, Hooks BM, Huber D, Petreanu L, Svoboda K (2011) Long-range neuronal circuits underlying the interaction between sensory and motor cortex. Neuron 72:111-123. CrossRef Medline

Markram H, Toledo-Rodriguez M, Wang Y, Gupta A, Silberberg G, Wu C (2004) Interneurons of the neocortical inhibitory system. Nat Rev Neurosci 5:793-807. CrossRef Medline

Mathon B, Nassar M, Simonnet J, Le Duigou C, Clemenceau S, Miles R, Fricker D (2015) Increasing the effectiveness of intracerebral injections in adult and neonatal mice: a neurosurgical point of view. Neurosci Bull. 31:685-696. CrossRef Medline

McNaughton BL, Battaglia FP, Jensen O, Moser EI, Moser MB (2006) Path integration and the neural basis of the 'cognitive map.' Nat Rev Neurosci 7:663-678. CrossRef Medline

Nagel G, Szellas T, Huhn W, Kateriya S, Adeishvili N, Berthold P, Ollig D, Hegemann P, Bamberg E (2003) Channelrhodopsin-2, a directly light- gated cation-selective membrane channel. Proc Natl Acad Sci U S A 100: 13940-13945. CrossRef Medline

Nassar M, Simonnet J, Lofredi R, Cohen I, Savary E, Yanagawa Y, Miles R, Fricker D (2015) Diversity and overlap of parvalbumin and somatostatin expressing interneurons in mouse presubiculum. Front Neural Circ 9:20. CrossRef Medline

Neher E, Sakaba T (2008) Multiple roles of calcium ions in the regulation of neurotransmitter release. Neuron 59:861-872. CrossRef Medline

Packer AM, Yuste R (2011) Dense, unspecific connectivity of neocortical parvalbumin-positive interneurons: a canonical microcircuit for inhibition? J Neurosci 31:13260-13271. CrossRef Medline

Paxinos G, Franklin KB (2013) The mouse brain in stereotaxic coordinates, Ed 4. Amsterdam: Elsevier-Academic.

Peng Y, Barreda Tomás FJ, Klisch C, Vida I, Geiger JR (2017) Layer-specific organization of local excitatory and inhibitory synaptic connectivity in the rat presubiculum. Cereb Cortex 27:2435-2452. CrossRef Medline

Peyrache A, Lacroix MM, Petersen PC, Buzsáki G (2015) Internally organized mechanisms of the head direction sense. Nat Neurosci 18:569-575. CrossRef Medline

Pouille F, Scanziani M (2001) Enforcement of temporal fidelity in pyramidal cells by somatic feed-forward inhibition. Science 293:1159-1163. CrossRef Medline

Preston-Ferrer P, Coletta S, Frey M, Burgalossi A (2016) Anatomical organization of presubicular head-direction circuits. eLife 5:e14592. CrossRef Medline

Rowland DC, Weible AP, Wickersham IR, Wu H, Mayford M, Witter MP, Kentros CG (2013) Transgenically targeted rabies virus demonstrates a major monosynaptic projection from hippocampal area CA2 to medial entorhinal layer II neurons. J Neurosci 33:14889-14898. CrossRef Medline

Simonnet J, Eugène E, Cohen I, Miles R, Fricker D (2013) Cellular neuroanatomy of rat presubiculum. Eur J Neurosci 37:583-597. CrossRef Medline

Simonnet J, Nassar M, Stella F, Cohen I, Mathon B, Boccara CN, Miles R, Fricker D (2017) Activity dependent feedback inhibition may maintain head direction signals in mouse presubiculum. Nat Commun 8:16032. CrossRef Medline

Stackman RW, Taube JS (1997) Firing properties of head direction cells in the rat anterior thalamic nucleus: dependence on vestibular input. J Neurosci 17:4349-4358. CrossRef Medline

Stokes CC, Isaacson JS (2010) From dendrite to soma: dynamic routing of inhibition by complementary interneuron microcircuits in olfactory cortex. Neuron 67:452-465. CrossRef Medline

Sugar J, Witter MP, van Strien NM, Cappaert NL (2011) The retrosplenial cortex: intrinsic connectivity and connections with the (para)hippocampal region in the rat: an interactive connectome. Front Neurosci 5:7. CrossRef Medline

Taniguchi H, He M, Wu P, Kim S, Paik R, Sugino K, Kvitsiani D, Fu Y, Lu J, Lin Y, Miyoshi G, Shima Y, Fishell G, Nelson SB, Huang ZJ (2011) A resource of Cre driver lines for genetic targeting of GABAergic neurons in cerebral cortex. Neuron 71:995-1013. CrossRef Medline

Taube JS (1995) Head direction cells recorded in the anterior thalamic nuclei of freely moving rats. J Neurosci 15:70-86. CrossRef Medline

Taube JS (2007) The head direction signal: origins and sensory-motor integration. Annu Rev Neurosci 30:181-207. CrossRef Medline

Taube JS, Muller RU (1998) Comparisons of head direction cell activity in the postsubiculum and anterior thalamus of freely moving rats. Hippocampus 8:87-108. CrossRef Medline

Trigo FF, Corrie JE, Ogden D (2009) Laser photolysis of caged compounds at $405 \mathrm{~nm}$ : photochemical advantages, localisation, phototoxicity and methods for calibration. J Neurosci Methods 180:9-21. CrossRef Medline

Tukker JJ, Tang Q, Burgalossi A, Brecht M (2015) Head-directional tuning and theta modulation of anatomically identified neurons in the presubiculum. J Neurosci 35:15391-15395. CrossRef Medline

van Groen T, Wyss JM (1990a) Connections of the retrosplenial granular a cortex in the rat. J Comp Neurol 300:593-606. CrossRef Medline

van Groen T, Wyss JM (1990b) The connections of presubiculum and parasubiculum in the rat. Brain Res 518:227-243. CrossRef Medline

van Groen T, Wyss JM (1990c) The postsubicular cortex in the rat: characterization of the fourth region of the subicular cortex and its connections. Brain Res 529:165-177. CrossRef Medline

van Groen T, Wyss JM (1992) Connections of the retrosplenial dysgranular cortex in the rat. J Comp Neurol 315:200-216. CrossRef Medline 
van Groen T, Wyss JM (1995) Projections from the anterodorsal and anteroventral nucleus of the thalamus to the limbic cortex in the rat. J Comp Neurol 358:584-604. CrossRef Medline

van Strien NM, Cappaert NL, Witter MP (2009) The anatomy of memory: an interactive overview of the parahippocampal-hippocampal network. Nat Rev Neurosci 10:272-282. CrossRef Medline

Vogt BA, Miller MW (1983) Cortical connections between rat cingulate cortex and visual, motor, and postsubicular cortices. J Comp Neurol 216: 192-210. CrossRef Medline

Whitmire CJ, Stanley GB (2016) Rapid sensory adaptation redux: a circuit perspective. Neuron 92:298-315. CrossRef Medline

Wilent WB, Contreras D (2005) Dynamics of excitation and inhibition underlying stimulus selectivity in rat somatosensory cortex. Nat Neurosci 8:1364-1370. CrossRef Medline
Williams SR, Mitchell SJ (2008) Direct measurement of somatic voltage clamp errors in central neurons. Nat Neurosci 11:790-798. CrossRef Medline

Winter SS, Clark BJ, Taube JS (2015) Disruption of the head-direction cell network impairs the parahippocampal grid cell signal. Science 347:870 874. CrossRef Medline

Wu GK, Arbuckle R, Liu BH, Tao HW, Zhang LI (2008) Lateral sharpening of cortical frequency tuning by approximately balanced inhibition. Neuron 58:132-143. CrossRef Medline

Yoshimura Y, Callaway EM (2005) Fine-scale specificity of cortical networks depends on inhibitory cell type and connectivity. Nat Neurosci 8:1552-1559. CrossRef Medline

Yoshimura Y, Dantzker JL, Callaway EM (2005) Excitatory cortical neurons form fine-scale functional networks. Nature 433:868-873. CrossRef Medline 